ARTICLE

DOI: $10.1038 / s 41467-018-04703-w$

OPEN

\title{
Nanoscale metal-organic frameworks enhance radiotherapy to potentiate checkpoint blockade immunotherapy
}

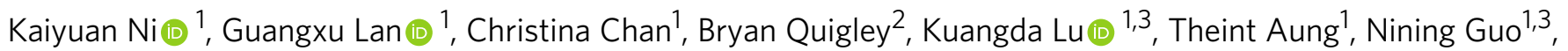
Patrick La Riviere ${ }^{2}$, Ralph R. Weichselbaum ${ }^{3} \&$ Wenbin Lin (1) 1,3

Checkpoint blockade immunotherapy enhances systemic antitumor immune response by targeting $T$ cell inhibitory pathways; however, inadequate $T$ cell infiltration has limited its anticancer efficacy. Radiotherapy (RT) has local immunomodulatory effects that can alter the microenvironment of irradiated tumors to synergize with immune checkpoint blockade. However, even with high doses of radiation, RT has rarely elicited systemic immune responses. Herein, we report the design of two porous $\mathrm{Hf}$-based nanoscale metal-organic frameworks (nMOFs) as highly effective radioenhancers that significantly outperform $\mathrm{HfO}_{2}$, a clinically investigated radioenhancer in vitro and in vivo. Importantly, the combination of nMOF-mediated low-dose RT with an anti-programmed death-ligand 1 antibody effectively extends the local therapeutic effects of RT to distant tumors via abscopal effects. Our work establishes the feasibility of combining nMOF-mediated RT with immune checkpoint blockade to elicit systemic antitumor immunity in non-T cell-inflamed tumor phenotypes without normal tissue toxicity, promising to broaden the application of checkpoint blockade immunotherapy.

\footnotetext{
${ }^{1}$ Department of Chemistry, The University of Chicago, Chicago, IL 60637, USA. ${ }^{2}$ Department of Radiology, The University of Chicago, Chicago, IL 60637, USA. ${ }^{3}$ Department of Radiation and Cellular Oncology and The Ludwig Center for Metastasis Research, The University of Chicago, Chicago, IL 60637, USA. These authors contributed equally: Kaiyuan Ni, Guangxu Lan. Correspondence and requests for materials should be addressed to W.L. (email: wenbinlin@uchicago.edu)
} 
C ancer immunotherapy is becoming an important treatment modality alongside surgery, radiotherapy (RT), and chemotherapy for certain cancers. ${ }^{1,2}$ In its host-protective role, the immune system functions to detect and eliminate foreign entities, such as tumors. However, growing tumor masses can dysregulate signaling pathways, immune suppressive cells/cytokines, and effector molecules, thus preventing immune cells from recognizing and killing tumor cells. ${ }^{3,4}$ In checkpoint blockade immunotherapy, immunosuppressive pathways regulating $\mathrm{T}$ cells are blocked to enhance systemic antitumor immune responses. ${ }^{5}$ Programmed cell death protein 1 (PD-1) and its two ligands (PDL1 and PD-L2) represent key pathways for immunosuppression. ${ }^{6}$ The interaction of PD-1 with either of its ligands inhibits kinase signaling pathways that are responsible for $\mathrm{T}$ cell activation, reducing effector $\mathrm{T}$ cell activity in tumors. Several anti-PD-1 and anti-PD-L1 antibodies have recently found clinical success in a subset of immunogenic tumors such as melanomas, non-smallcell lung cancer, and genitourinary cancers. ${ }^{7-9}$ However, targeting the PD-1/PD-L1 axis alone is insufficient to sustain an effective and durable response for most tumors, partly due to inadequate $\mathrm{T}$ cell infiltration into the cancerous tissues in non-immunogenic tumors. ${ }^{10,11}$ Therefore, immunomodulatory adjuvant treatments are actively pursued to synergize with checkpoint blockade immunotherapy to break immune tolerance and potentiate antitumor immunity in the host system. ${ }^{12-14}$

RT is a local treatment prevalently used across many cancer types in the clinic. High-dose, hypofractionated RT is studied as immunomodulatory adjuvant treatment to enhance checkpoint blockade immunotherapy in clinical trials. ${ }^{15-18} \mathrm{RT}$ inflicts ionization damage to tumor tissues in an X-ray dose-dependent manner and its efficacy is usually limited by the maximum radiation dose that can be given to a tumor mass without incurring significant injuries to the neighboring tissues or organs. $^{19}$ Conformation and/or intensity-modulated radiotherapies have been developed over the past few decades to provide greater spatial control on X-ray energy deposition, thus alleviating normal tissue toxicity. ${ }^{20}$ Reducing X-ray doses while maintaining sufficient ionization damage to tumors by using tumor-targeted radioenhancers can further minimize side effects to the surrounding tissues and also make RT a more compatible and effective adjuvant treatment to enhance checkpoint blockade immunotherapy. ${ }^{21,22}$

Heavy metal-based nanoparticles (NPs) such as $\mathrm{Au}$ and $\mathrm{HfO}_{2}$ NPs have been shown as promising radioenhancers. ${ }^{23-26}$ NPs of high atomic $(Z)$ number elements have high X-ray absorption coefficients and, when selectively deposited in tumors, can significantly increase radiosensitivity difference between healthy and tumor tissues, thus reducing radiation dose without impacting anticancer activity. NP radioenhancers can thus potentially increase the therapeutic index of RT by sparing healthy tissues of high-dose radiation. For example, $\mathrm{HfO}_{2} \mathrm{NPs}$ have been tested as a radioenhancer in several clinical trials for the treatment of soft tissue sarcomas, head and neck cancer, and other tumors. ${ }^{27-29}$ Yet, radiosensitizers with stronger radioenhancing effects are still needed for locally sensitizing tumors and eliciting immunomodulatory effects to enhance checkpoint blockade immunotherapy. ${ }^{30,31}$

Nanoscale metal-organic frameworks (nMOFs) have emerged as an important class of nanomaterials for biomedical applications due to their high porosity, multifunctionality, and biocompatibility. ${ }^{32-35}$ The ordered and porous structures of nMOFs have been shown to avoid self-quenching of photosensitizers and facilitate the diffusion of reactive oxygen species (ROS), leading to improved efficacy in photodynamic therapy. We hypothesized that electron-dense Hf-oxo-based secondary building units (SBUs) in nMOFs can preferentially absorb X-rays over tissues to enhance radiosensitization, while porous structures of nMOFs can facilitate the diffusion of generated ROS to exert cytotoxic effects, allowing for the design of a new generation of radioenhancers with superior radiotherapeutic efficacy.

Herein, we report a treatment strategy that combines nMOFmediated RT and checkpoint blockade immunotherapy to achieve systemic rejection of colorectal tumors in mouse models. Two Hfbased nMOFs, $\mathrm{Hf}_{6}$-DBA and $\mathrm{Hf}_{12}$-DBA (DBA $=2,5-\mathrm{di}(p$-benzoato)aniline), are designed as radioenhancers by taking advantage of the electron-dense $\mathrm{Hf}_{6} \mathrm{O}_{4}(\mathrm{OH})_{4}$ and $\mathrm{Hf}_{12} \mathrm{O}_{8}(\mathrm{OH})_{14}$ SBUs

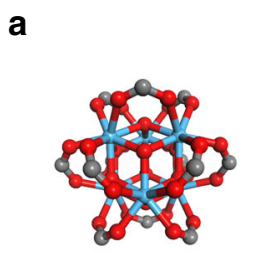

$\mathrm{Hf}_{6}$ cluster
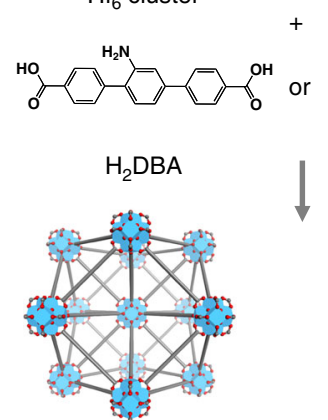

$\mathrm{Hf}_{6}$-DBA or $\mathrm{Hf}_{6}$-DBAn

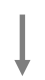

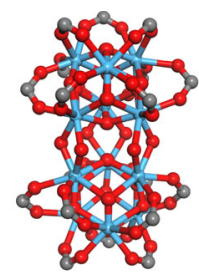

$\mathrm{Hf}_{12}$ cluster
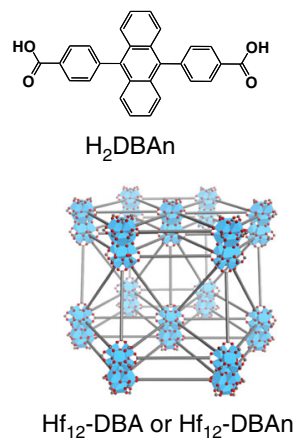
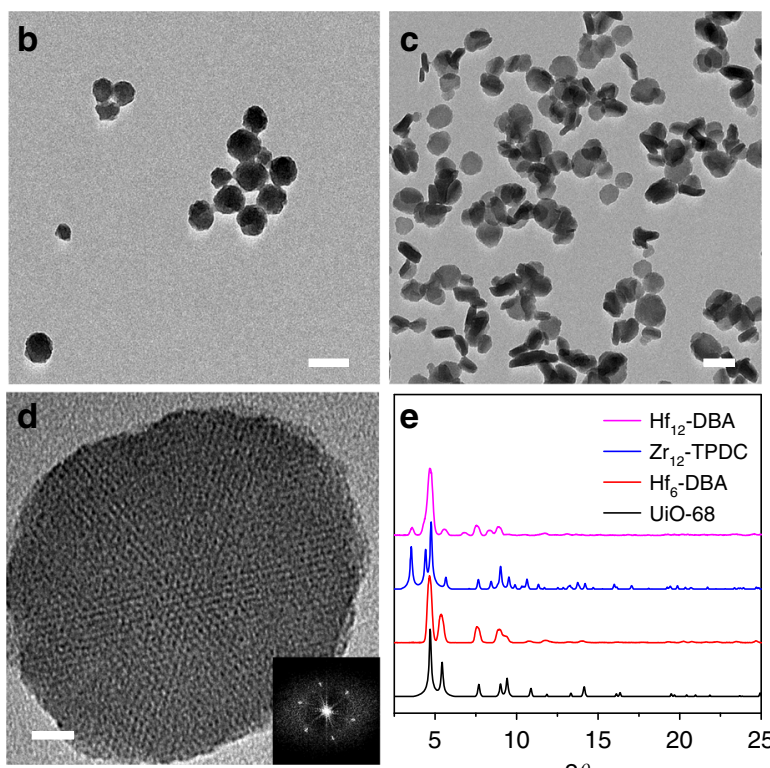

Fig. 1 Structures and morphologies of $\mathrm{Hf}_{6}-\mathrm{DBA}$ and $\mathrm{Hf}_{12}-\mathrm{DBA}$. a Synthesis of $\mathrm{Hf}_{6}-\mathrm{DBA}, \mathrm{Hf}_{6}-\mathrm{DBAn} \mathrm{Hf}_{12}-\mathrm{DBA}$, and $\mathrm{Hf}_{12}-\mathrm{DBAn}$. Transmission electron microscopy (TEM) images of $\mathrm{Hf}_{6}-\mathrm{DBA}(\mathbf{b})$ and $\mathrm{Hf}_{12}-\mathrm{DBA}(\mathbf{c}, \mathbf{d})$ with its fast Fourier transform (FFT) pattern shown in the inset of $\mathbf{d}$. Scale bar $=100$ nm (b, c) or $10 \mathrm{~nm}$ (d). e PXRD patterns of $\mathrm{Hf}_{6}$-DBA and $\mathrm{Hf}_{12}$-DBA nMOFs in comparison to those of UiO-68 and $\mathrm{Zr}_{12}-\mathrm{TPDC}$. For $\mathrm{TEM}$ images, each $\mathrm{nMOF}$ was repeated at least five times and they all showed similar results 
as X-ray absorbers to generate ROS and the open channels as well as small nMOF dimensions to facilitate ROS diffusion. Hydroxyl radical generation studies show that both nMOFs display higher radioenhancing efficiencies than clinically investigated $\mathrm{HfO}_{2} \mathrm{NPs}$, which is supported by clonogenic assays and in vivo antitumor efficacy studies. These comparisons also reveal the superior efficacy of $\mathrm{Hf}_{12}$-DBA over $\mathrm{Hf}_{6}$-DBA, likely a result of enhanced ROS production due to increased X-ray absorption and more facile ROS diffusion owing to thin nanoplate structures. We also demonstrate in vivo that nMOF-mediated low-dose RT given in conjunction with an anti-PD-L1 antibody not only eradicates local tumors but also rejectes/regresses distant tumors through systemic antitumor immunity on a syngeneic CT26 colorectal cancer model. Furthermore, we profile the immune responses to probe the underlying mechanisms to provide further insight into this high level of abscopal effects from a combination of nMOFmediated RT and checkpoint blockade immunotherapy.

\section{Results}

Synthesis and characterization of $\mathrm{Hf}_{6}-\mathrm{DBA}$ and $\mathrm{Hf}_{12}-\mathrm{DBA}$ nMOFs. By tuning the temperature and modulators, two Hfbased nMOFs with different SBUs, $\mathrm{Hf}_{6}$-DBA with a formula of $\mathrm{Hf}_{6}\left(\mu_{3}-\mathrm{O}\right)_{4}\left(\mu_{3}-\mathrm{OH}\right)_{4}(\mathrm{DBA})_{6}$ and $\mathrm{Hf}_{12}-\mathrm{DBA}$ with a formula of $\mathrm{Hf}_{12}\left(\mu_{3}-\mathrm{O}\right)_{8}\left(\mu_{3}-\mathrm{OH}\right)_{8}\left(\mu_{2}-\mathrm{OH}\right)_{6}(\mathrm{DBA})_{9}$, were synthesized via solvothermal reactions (Fig. 1a). ${ }^{35,36}$ Transmission electron microscopy (TEM) imaging studies showed that $\mathrm{Hf}_{6}$-DBA exhibited spherical morphology with a diameter of approximately $68 \mathrm{~nm}$, while $\mathrm{Hf}_{12}$-DBA possessed a plate-like morphology of $\sim 98 \mathrm{~nm}$ in diameter and $\sim 30 \mathrm{~nm}$ in thickness. Both nMOFs showed good dispersity in ethanol (Fig. 1b-d and Supplementary
Figs. 1 and 2). Dynamic light scattering measurements gave a number-averaged diameter and polydispersity index of $116.0 \pm$ 0.9 and $0.07 \pm 0.01 \mathrm{~nm}$, respectively, for $\mathrm{Hf}_{6}$-DBA and $102.1 \pm 4.1$ and $0.08 \pm 0.02 \mathrm{~nm}$, respectively, for $\mathrm{Hf}_{12}$-DBA (Supplementary Fig. 3). The powder X-ray diffraction (PXRD) pattern of $\mathrm{Hf}_{6}$ DBA was identical to that of UiO- $68^{36}$, while the PXRD pattern of $\mathrm{Hf}_{12}$-DBA was identical to that of $\mathrm{Zr}_{12}-\mathrm{TPDC}^{37}$, indicative of their crystalline nature and different topological structures (Fig. 1e). Thermogravimetric analysis results of $\mathrm{Hf}_{6}-\mathrm{DBA}$ or $\mathrm{Hf}_{12^{-}}$ DBA matched the weight losses expected for their decomposition to $\mathrm{HfO}_{2}$ (Supplementary Fig. 4). Nitrogen sorption measurements showed that $\mathrm{Hf}_{6}$-DBA possessed a Brunauer-Emmett-Teller (BET) surface area of $804.4 \mathrm{~m}^{2} / \mathrm{g}$, whereas $\mathrm{Hf}_{12}$-DBA exhibited a BET surface area of $463.9 \mathrm{~m}^{2} / \mathrm{g}$ (Supplementary Fig. 5). Ultrasmall solid $\mathrm{HfO}_{2}$ NPs with a diameter of $\sim 10 \mathrm{~nm}$ were also synthesized and used as a control (Supplementary Fig. 6).

Due to strong coordination between $\mathrm{Hf}^{4+}$ ions and carboxylate groups, both nMOFs were stable in aqueous suspensions. After incubation in RPMI-1640 cell culture medium for $240 \mathrm{~h}$ or upon $\mathrm{X}$-ray irradiation at a dose of $16 \mathrm{~Gy}$, the PXRD patterns of $\mathrm{Hf}_{12^{-}}$ DBA were identical to that of the pristine sample, indicating the structural stability of $\mathrm{Hf}_{12}$-DBA under physiological conditions and upon X-ray irradiation (Supplementary Figs. 7 and 8).

Hydroxyl radical formation. Hydroxyl radicals, the major cytotoxic radical species from ionizing radiation, were detected via aminophenylfluorescein (APF) assay, in which APF reacts with hydroxyl radicals to give bright green fluorescence (excitation/emission maxima $490 / 515 \mathrm{~nm}$ ). We first determined the percentage of APF trapped in $\mathrm{Hf}_{6}$-DBA or $\mathrm{Hf}_{12}$-DBA via

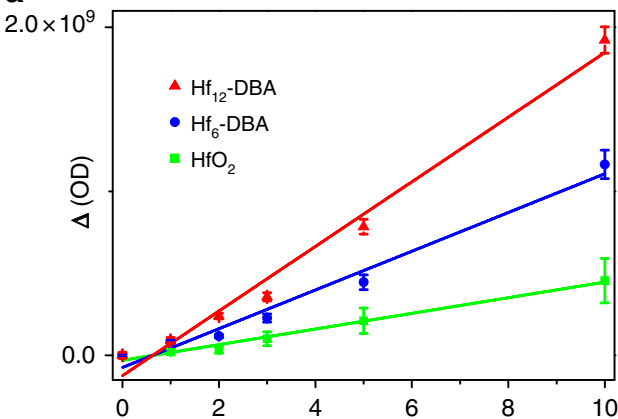

b

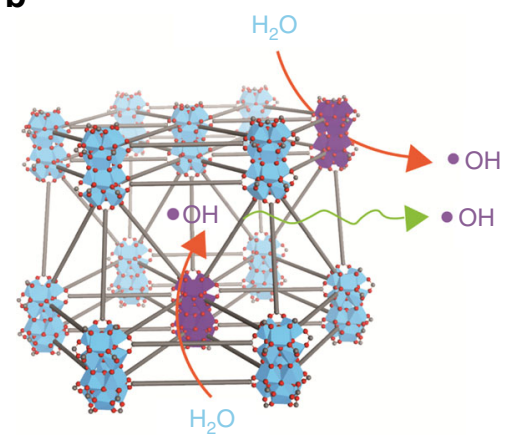

C

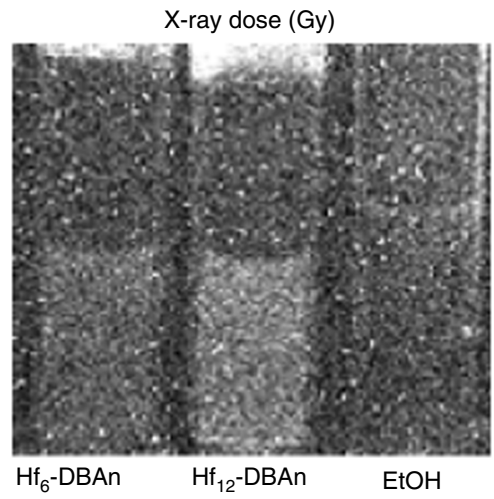

d

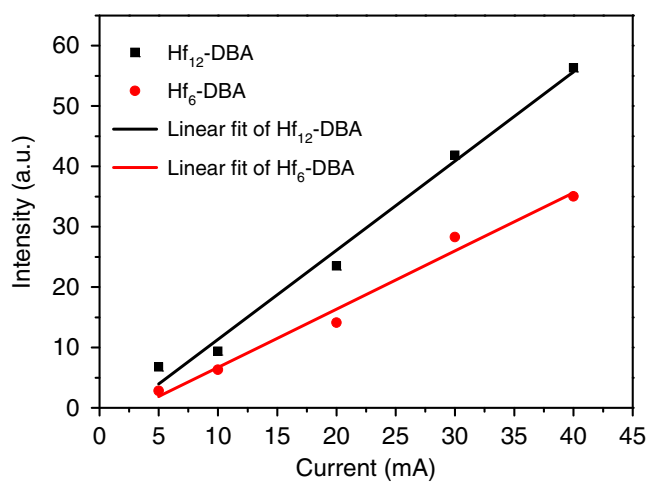

Fig. 2 Radioenhancing efficiency of $\mathrm{HfO}_{2}$ vs. $\mathrm{Hf}_{6}$-based and $\mathrm{Hf}_{12}$-based nMOFs. a Enhanced APF fluorescence of $\mathrm{HfO}_{2}, \mathrm{Hf}_{6}-\mathrm{DBA}$, and $\mathrm{Hf}_{12}$ - $-\mathrm{DBA}$ over $\mathrm{H}_{2} \mathrm{O}$ at equivalent $\mathrm{Hf}$ concentrations of $20 \mu \mathrm{M} . n=6$. $\mathbf{b}$ Illustration of efficient hydroxyl radical generation upon X-ray irradiation and diffusion through porous $\mathrm{Hf}_{12}{ }^{-}$ DBA nanoplates. c Optical images of radioluminescence from $\mathrm{Hf}_{6}-\mathrm{DBAn}\left(1 \mathrm{mM}\right.$ in ethanol), $\mathrm{Hf}_{12}$-DBAn ( $\mathrm{mM}$ in ethanol), and pure ethanol at an X-ray dose rate of $2.93 \mathrm{~Gy} / \mathrm{min}$. $\mathbf{d}$ Linear fits of radioluminescence intensities with respect to X-ray tube currents of $\mathrm{Hf}_{6}-\mathrm{DBA}$ and $\mathrm{Hf}_{12}$-DBA after subtraction of pure ethanol background. Central data points and error bars represent mean \pm s.d. values, respectively. Hydroxyl detection result was obtained without repetition. The radioluminescence images were obtained with two repetitions to afford similar results 
detecting chemically produced hydroxyl radicals from Fenton's reaction by APF with and without the nMOF: the percentage of APF trapped in $\mathrm{Hf}_{6}$-DBA or $\mathrm{Hf}_{12}$-DBA equals to one minus the fluorescence intensity ratio of APF with nMOF over that of APF without nMOF (Supplementary Method 2 and Supplementary Figs. 9 and 10). We then irradiated $5 \mu \mathrm{M}$ APF in aqueous solution or in aqueous dispersion of $\mathrm{HfO}_{2}, \mathrm{Hf}_{6}$-DBA, or $\mathrm{Hf}_{12}$-DBA at an $\mathrm{Hf}$ concentration of $20 \mu \mathrm{M}$ with $\mathrm{X}$-ray in the dose range of 0 to $10 \mathrm{~Gy}$ and determined their fluorescence signals. After correcting for the percentage of APF trapped in the nMOF, we deduced the fluorescence intensity corresponding to the amounts of hydroxyl radicals generated by water, $\mathrm{HfO}_{2}, \mathrm{Hf}_{6}-\mathrm{DBA}$, and $\mathrm{Hf}_{12}$-DBA as shown in Supplementary Fig. 10. All four groups showed linear increases of hydroxyl radical generation with increasing X-ray dose. The relative enhancement of hydroxyl radical generation compared with water was obtained by subtracting the APF fluorescence intensity from water as shown in Fig. 2a. Compared to water, $\mathrm{HfO}_{2}, \mathrm{Hf}_{6}$-DBA, and $\mathrm{Hf}_{12}$-DBA enhanced hydroxyl generation by $14.3 \%, 33.6 \%$, or $55.3 \%$, respectively.

Radioluminescence. Upon X-ray irradiation, Hf-based MOFs were previously shown to transfer energy to anthracene-based bridging ligands, DBAn (DBAn $=2,5$-di $(p$-benzoato $)$ antheracene), to emit radioluminescence in the visible spectrum. ${ }^{32}$ Radioluminescence of Hf-DBAn-based MOFs can thus be used to probe their X-ray absorption efficiency. We synthesized $\mathrm{Hf}_{6}$ DBAn and $\mathrm{Hf}_{12}$-DBAn, two DBAn MOFs with $\mathrm{Hf}_{6}$ and $\mathrm{Hf}_{12}$ SBUs, for radioluminescence measurements to investigate the relationship between SBU structure and X-ray absorption efficiency (Supplementary Figs. 11 and 12). After degassing, $4 \mathrm{~mL}$ vials of $\mathrm{Hf}_{12}$-DBAn and $\mathrm{Hf}_{6}$-DBAn at an $\mathrm{Hf}$ concentration of 1 $\mathrm{mM}$ in ethanol along with the ethanol control were irradiated with X-rays at a maximum dose rate of $2.93 \mathrm{~Gy} / \mathrm{min}$ and their radioluminescence images were acquired using a CCD camera. As shown in Fig. 2c, $\mathrm{Hf}_{12}$-DBAn gave a much brighter radioluminescence signal compared to $\mathrm{Hf}_{6}-\mathrm{DBAn}$ and EtOH. Image processing software (ImageJ) was then used to calculate radioluminescence intensities by sampling the average pixel value of the vials and subtracting the average pixel value of pure ethanol background. The measured intensities were fit linearly as a function of X-ray tube current, which is proportional to the radiation dose (Fig. $2 \mathrm{~d}$ ). $\mathrm{Hf}_{12}$-DBAn had radioluminescence slope of $1.36 \pm 0.05,1.58$-fold higher than that of $\mathrm{Hf}_{6}$-DBAn $(0.86 \pm$ 0.04 , Supplementary Table 1$)$. This result indicated that $\mathrm{Hf}_{12^{-}}$ DBAn exhibited approximately 1.5 times higher X-ray absorption efficiency than $\mathrm{Hf}_{6}$-DBAn. Both hydroxyl radical generation and radioluminescence measurements thus demonstrated that $\mathrm{Hf}_{12^{-}}$ DBA is an excellent radioenhancer for RT.

Clonogenic assay. Time-dependent cellular uptake of $\mathrm{HfO}_{2}, \mathrm{Hf}_{6^{-}}$ DBA, and $\mathrm{Hf}_{12}$-DBA in CT26 cells from 1 to $8 \mathrm{~h}$ demonstrated efficient cellular uptake of nMOFs and $4 \mathrm{~h}$ incubation was chosen as the time point for further in vitro studies (Supplementary Method 2 and Supplementary Fig. 13). Facile nMOF endocytosis was confirmed by confocal imaging; nMOFs labeled with Rhodamine $\mathrm{B}\left(\mathrm{Hf}_{6}\right.$-DBA-R and $\mathrm{Hf}_{12}$-DBA-R) co-localized with Lysotracker Green that labeled endo/lysosomes in both $\mathrm{Hf}_{6}$-DBAtreated or $\mathrm{Hf}_{12}$-DBA-treated cells (Supplementary Method 3 and Supplementary Fig. 14).

Clonogenic assays were performed to assess the colonyforming potential of cells treated with nMOFs at an $\mathrm{Hf}$ concentration of $20 \mu \mathrm{M}$ for $4 \mathrm{~h}$ followed by irradiation with either X-ray or ${ }^{60} \mathrm{Co}$ isotope $\gamma$-ray source at $0-16$ Gy. Treated cells were trypsinized, re-seeded, and cultured for 10-20 days and the clones were counted and plotted with the survival fraction as

\begin{tabular}{|c|c|c|c|c|c|c|c|}
\hline & REF $_{10}$ & 4T1 & TUBO & HeLa & CT26 & JSQ3 & SQ20B \\
\hline \multirow[t]{3}{*}{ X-ray } & $\mathrm{HfO}_{2}$ & 1.09 & 1.13 & 1.10 & 1.03 & 1.00 & 1.16 \\
\hline & $\mathrm{Hf}_{6}-\mathrm{DBA}$ & 1.11 & 1.31 & 1.25 & 1.19 & 1.10 & 1.29 \\
\hline & $\mathrm{Hf}_{12}-\mathrm{DBA}$ & 1.45 & 1.73 & 1.43 & 1.49 & 1.65 & 1.56 \\
\hline \multirow[t]{3}{*}{$\gamma$-ray } & $\mathrm{HfO}_{2}$ & 1.06 & 1.03 & 1.11 & 1.01 & 1.00 & 1.00 \\
\hline & $\mathrm{Hf}_{6}-\mathrm{DBA}$ & 1.15 & 1.27 & 1.31 & 1.06 & 1.06 & 1.08 \\
\hline & $\mathrm{Hf}_{12}$-DBA & 1.26 & 1.44 & 1.47 & 1.14 & 1.10 & 1.23 \\
\hline
\end{tabular}

shown in Supplementary Figs. 15 and 16. Radiation enhancement factor at $10 \%$ survival dose $\left(\mathrm{REF}_{10}\right)$ was calculated as the ratio of equivalent irradiation doses needed to give $10 \%$ survival rate for the phosphate-buffered saline (PBS) control group over that for the experimental group.

As shown in Table $1,20 \mu \mathrm{M} \mathrm{HfO}$ showed only moderate radioenhancing effect compared to $\mathrm{PBS}$ and exhibited much smaller $\mathrm{REF}_{10}$ values than $\mathrm{Hf}_{6}$-DBA and $\mathrm{Hf}_{12}$-DBA in all cell lines examined, which is consistent with the APF assay results. Interestingly, at the same $\mathrm{Hf}$ concentration, $\mathrm{Hf}_{12}$-DBA outperformed $\mathrm{Hf}_{6}-\mathrm{DBA}$, with $\mathrm{REF}_{10}$ values from 1.45 to 1.73 compared to those from 1.10 to 1.31 for $\mathrm{Hf}_{6}-\mathrm{DBA}$. $\mathrm{Hf}_{12}$-DBA thus exhibited superior radioenhancement over $\mathrm{Hf}_{6}$-DBA, likely due to enhanced X-ray absorption by the electron-dense $\mathrm{Hf}_{12}$ clusters and hydroxyl radical diffusion through the porous nanoplates (Fig. 2b). Upon irradiation with $\gamma$-rays from a ${ }^{60} \mathrm{Co}$ source, $\mathrm{Hf}_{12}$-DBA also exhibited higher radiosensitization $\left(\mathrm{REF}_{10}\right.$ $=1.10-1.47)$ than $\mathrm{HfO}_{2}$ and $\mathrm{Hf}_{6}-\mathrm{DBA}$, suggesting that $\mathrm{Hf}_{12}$-DBA is compatible with linear accelerators commonly used in the clinic.

DNA double-strand break analysis. To elucidate the anticancer mechanism of nMOF-based RT, we investigated DNA doublestrand break (DSB) and cell death pathways caused by nMOFs upon X-ray irradiation in CT26 cells. $\gamma$-H2AX, a phosphorylated protein that resulted from direct ionizing radiation or generated hydroxyl radicals to induce DNA damage repair, has been used as a sensitive biomarker for probing DSBs. ${ }^{38,39}$ Twenty-four hours after irradiation, significant red $\gamma$-H2AX fluorescence indicating DSBs was observed in the groups treated with Hf-based NPs, while no fluorescence was observed in groups either without Xray irradiation or without Hf-based NP (Supplementary Fig. 17). Hf-based NP-treated groups also showed significant increases in the percentage of cells with DSB foci compared with the PBS control (Supplementary Fig. 18). Quantitative flow cytometric analyses showed that cells treated with $\mathrm{Hf}_{12}$-DBA exhibited stronger red fluorescence than cells treated with $\mathrm{Hf}_{6}$-DBA or $\mathrm{HfO}_{2}$, confirming that $\mathrm{Hf}_{12}$-DBA induced stronger DNA DSB (Supplementary Fig. 19). $\mathrm{Hf}_{12}$-DBA additionally induced more foci per cell as shown in Fig. 3a, with $45.0 \pm 2.2,21.8 \pm 1.5,12.4 \pm$ 2.7, and $2.4 \pm 1.1$ foci per nucleus in $\mathrm{Hf}_{12}$-DBA-treated, $\mathrm{Hf}_{6^{-}}$ DBA-treated, $\mathrm{HfO}_{2}$-treated, and $\mathrm{PBS}$ treated cells, respectively (Fig. 3b). These results support potent radioenhancing efficiency of the unique $\mathrm{Hf}_{12}$ structure.

Apoptotic cell death analysis. The cell death pathways were then evaluated with Annexin V/Dead Cell Apoptosis Kit. Significant amounts of cells underwent apoptosis/necrosis when treated with $\mathrm{Hf}_{12}$-DBA and X-ray irradiation with only $71.6 \%$ healthy cells, compared to $92.8 \%$ and $88.0 \%$ healthy cells for $\mathrm{HfO}_{2}$ or $\mathrm{Hf}_{6}$-DBA plus X-ray irradiation (Fig. 3c). 90\% + cells remained healthy in dark controls or the PBS group with irradiation, indicating that 

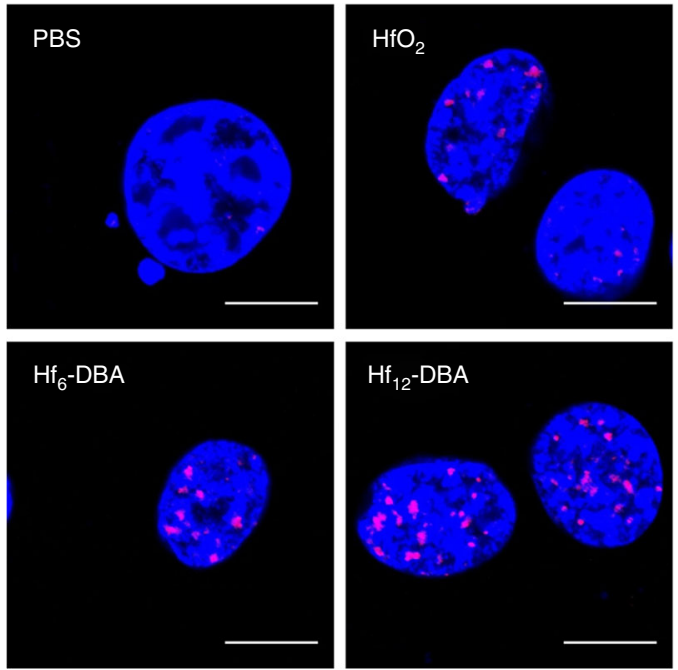

$\mathbf{C}$

(-)

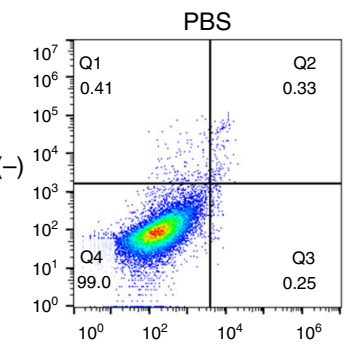

$\mathrm{Pl}$

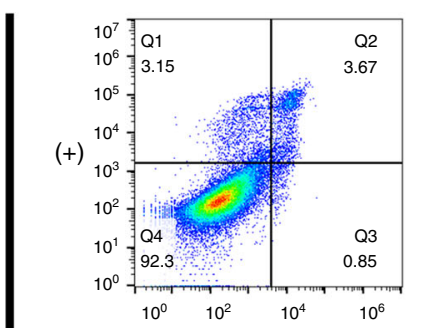

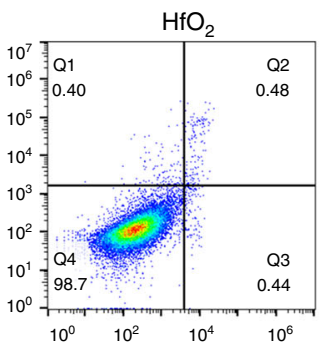
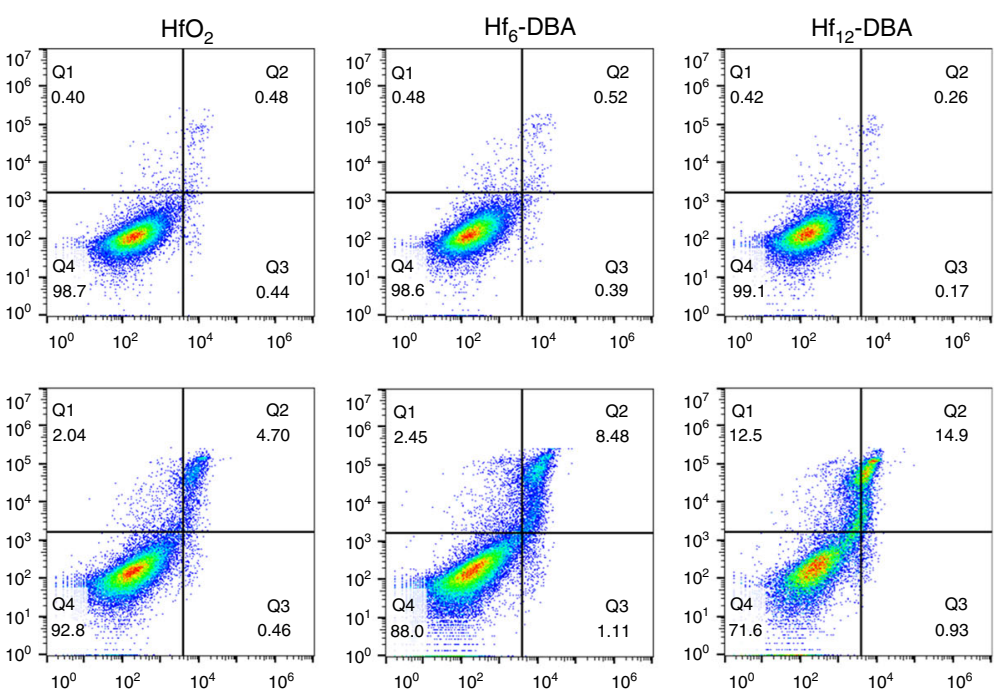

b

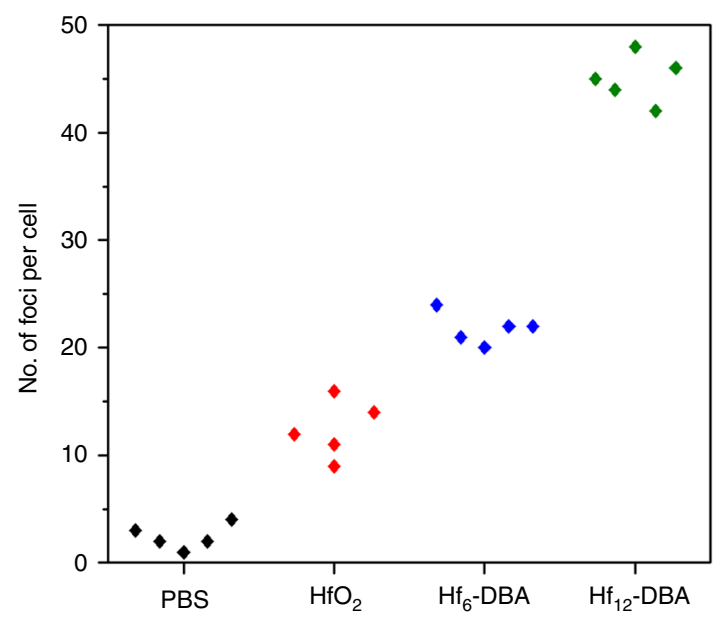

Annexin-V FITC

Fig. 3 In vitro mechanistic studies of nMOF-mediated RT cytotoxicity. a $\gamma$-H2AX assays showing the DSBs in CT26 cells treated with nMOFs and X-ray irradiation. Blue and red fluorescences show DAPI-stained nucleus and antibody-labeled $\gamma-\mathrm{H} 2 \mathrm{AX}$ in the cells, respectively. Scale bar $=10 \mu \mathrm{m}$. $\mathbf{b}$ Quantitative analysis of number of DBS foci per nucleus. c Annexin V/PI analysis of $\mathrm{CT} 26$ cells. Cells were incubated with $\mathrm{PBS}, \mathrm{HfO}_{2}, \mathrm{Hf}_{6}-\mathrm{DBA}$, or $\mathrm{Hf}_{12}{ }^{-}$ DBA with or without X-ray irradiation at a dose of $4 \mathrm{~Gy}$. The quadrants from lower left to upper left (counter clockwise) represent healthy, early apoptotic, late apoptotic, and necrotic cells, respectively. The percentage of cells in each quadrant was shown on the graphs. $(+)$ and $(-)$ refer to with and without irradiation, respectively. Both confocal images and flow cytometry results were obtained with two repetitions. One of two repetitions with similar results is shown

NP radioenhancers are not intrinsically cytotoxic and the lowdose X-ray showed negligible cytotoxicity without a NP radioenhancer. Taken together, $\mathrm{Hf}_{12}-\mathrm{DBA}$ is a significantly more efficient radioenhancer than both $\mathrm{HfO}_{2}$ and $\mathrm{Hf}_{6}$-DBA at equivalent $\mathrm{Hf}$ and X-ray doses.

In vivo antitumor efficacy. After demonstrating that $\mathrm{Balb} / \mathrm{c}$ mice dosed subcutaneously with $10 \mu \mathrm{mol} \mathrm{Hf}_{12}$-DBA (based on $\mathrm{Hf}$ ) showed no difference in body weight evolution compared with PBS control (Supplementary Fig. 20), we carried out in vivo efficacy studies with mice receiving a single nMOF injection followed by X-ray irradiation. A colorectal adenocarcinoma mouse model of single CT26 tumor-bearing BALB/c mice was employed to evaluate the radioenhancing effects and antitumor efficacy of $\mathrm{HfO}_{2}, \mathrm{Hf}_{6}$-DBA, and $\mathrm{Hf}_{12}$-DBA. When the tumors reached $100-150 \mathrm{~mm}^{3}$ in volume, $\mathrm{Hf}_{6}$-DBA, $\mathrm{Hf}_{12}$-DBA, or $\mathrm{HfO}_{2}$ NPs were injected intratumorally at equivalent $\mathrm{Hf}$ doses of $1 \mu \mathrm{mol}$ followed by daily X-ray irradiation at a dose of $1 \mathrm{~Gy} /$ fraction (120 $\mathrm{kVp}, 20 \mathrm{~mA}, 2 \mathrm{~mm} \mathrm{Cu}$ filter) for a total of 10 fractions on consecutive days. An additional high-dose group of $\mathrm{HfO}_{2}$ at $3.2 \mu \mathrm{mol}$ was employed to further illustrate the difference between nMOFs and $\mathrm{HfO}_{2}$.

As shown in Fig. 4a, two Hf-based nMOFs afforded better local RT outcomes than $\mathrm{HfO}_{2}$. $\mathrm{Hf}_{12}$-DBA effectively regressed the locally irradiated tumors after a total of $10 \mathrm{~Gy}$ X-ray irradiation. In comparison, $\mathrm{Hf}_{6}$-DBA-treated and $\mathrm{HfO}_{2}$-treated groups showed only moderate anticancer efficacy, even after increasing the $\mathrm{HfO}_{2}$ dose 3.2-fold. The body weights of mice remained consistent regardless of treatment (Fig. $4 \mathrm{~b}$ ), suggesting that there was no systemic toxicity. Inductively coupled plasma-mass 

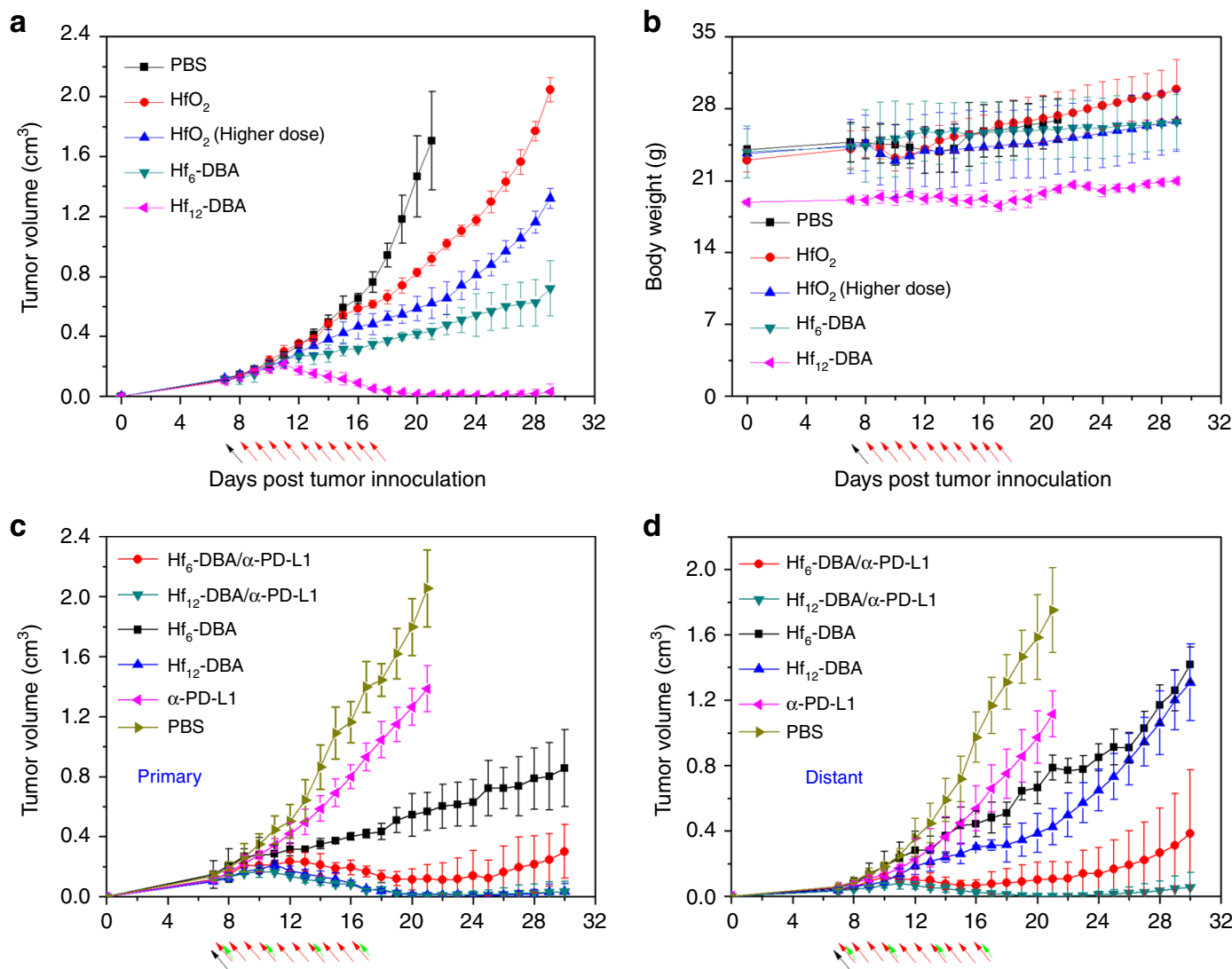

Days post tumor inoculation
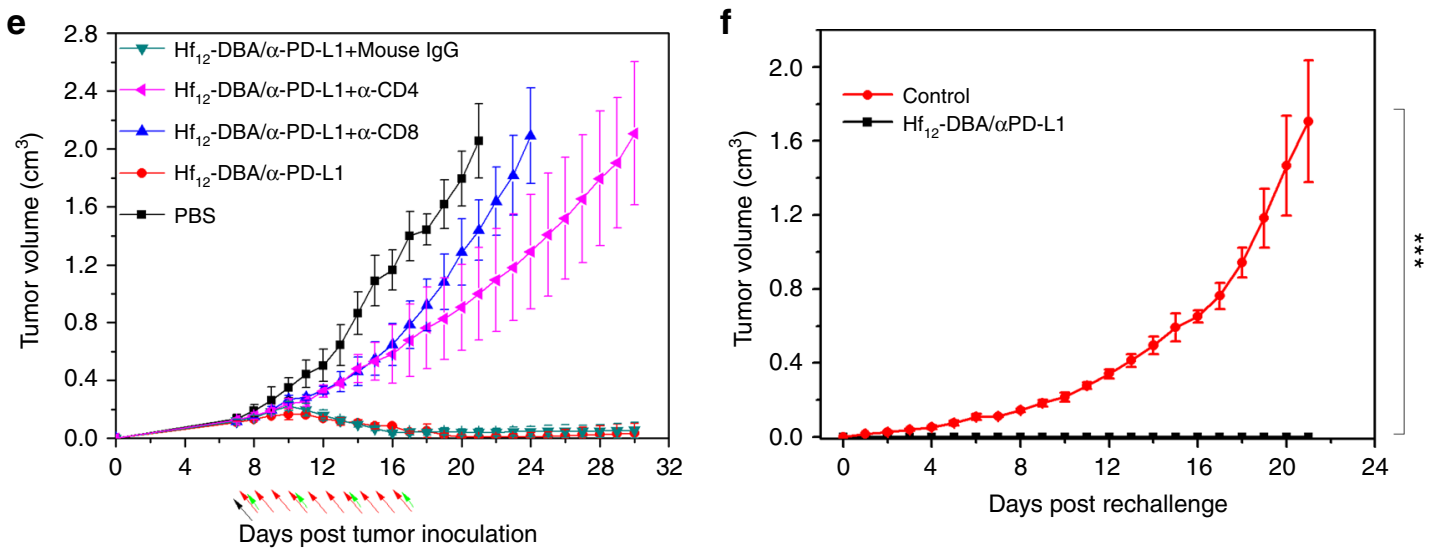

Fig. 4 In vivo studies comparing antitumor efficacy of Hf-based NPs. Tumor growth inhibition curves (a) and body weights (b) after RT treatment in the single CT26 tumor-bearing mice treated with $\mathrm{PBS}, \mathrm{HfO}_{2}$ (low and high doses), $\mathrm{Hf}_{6}-\mathrm{DBA}$, or $\mathrm{Hf}_{12}-\mathrm{DBA}$. Tumor growth curves of $\mathbf{c}$ primary tumors and $\mathbf{d}$ distant tumors of CT26 bilateral tumor-bearing mice treated with $\mathrm{Hf}_{6}$-DBA (with or without anti-PD-L1 antibody), Hf 12 -DBA (with or without anti-PD-L1 antibody), anti-PD-L1 antibody, or PBS with X-rays irradiation. e Tumor growth curves of CT26 tumor-bearing mice with T cell depletion and treated with $\mathrm{Hf}_{12}$-DBA, anti-PD-L1 antibody, and X-ray irradiation. $\mathbf{f}$ Tumor growth curves after the tumor rechallenge with CT26 cells. Treatment began on day 7 after tumor inoculation when the tumor reached a volume of $100-150 \mathrm{~mm}^{3}$. X-ray irradiation was carried out on mice $12 \mathrm{~h}$ after the i.t. injection of PBS or NPs on 10 consecutive days at a dose of $1 \mathrm{~Gy} /$ fraction ( $120 \mathrm{kVp}, 20 \mathrm{~mA}, 2 \mathrm{~mm}$ Cu filter). Antibody was given intraperitoneally every 3 days at a dose of $75 \mu \mathrm{g} /$ mouse. Black, red, and green arrows refer to the times of PBS or nanoparticles injections, X-ray irradiation, and antibody administration, respectively. $n=6$. $P$ values for comparisons with controls by $t$ test are indicated by three asterisks: ${ }^{\star \star \star} P<0.001$. Central data points and error bars represent mean \pm s.d. values, respectively. The $\mathrm{Hf}_{12}$-DBA with anti-PD-L1 treatment group was repeated once

spectrometry analysis showed that the amounts of $\mathrm{Hf}_{12}$-DBA in tumors slowly decreased following intratumoral injection (Supplementary Fig. 21).

In vitro and in vivo evaluation of immunogenicity. The immunogenic cell death (ICD) induced by Hf NP-mediated radiation treatment was investigated by detecting cell-surface expression of calreticulin (CRT) both in vitro and in vivo. ${ }^{40}$ As shown in Fig. 5a and Supplementary Fig. 22, more green fluorescence was observed in the group treated with nMOFs compared to groups treated with either $\mathrm{PBS}$ or $\mathrm{HfO}_{2}$ under confocal laser scanning microscopy (CLSM), suggesting higher immunogenicity of nMOF-mediated RT treatment. Quantitative flow cytometry analyses confirmed that $\mathrm{Hf}_{12}$-DBA showed significantly higher 

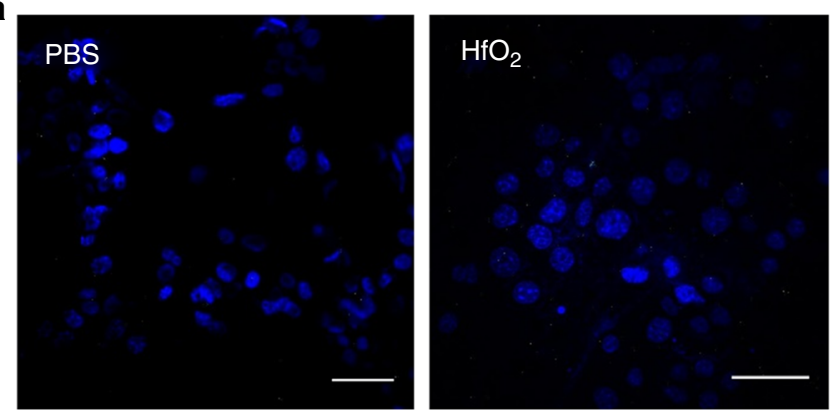

b

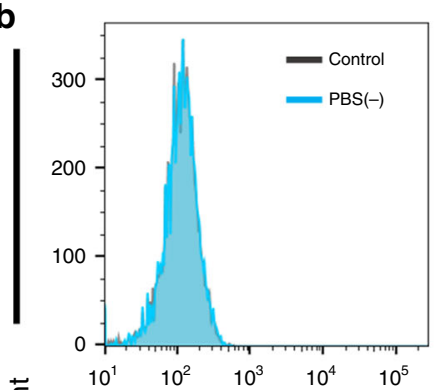

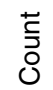
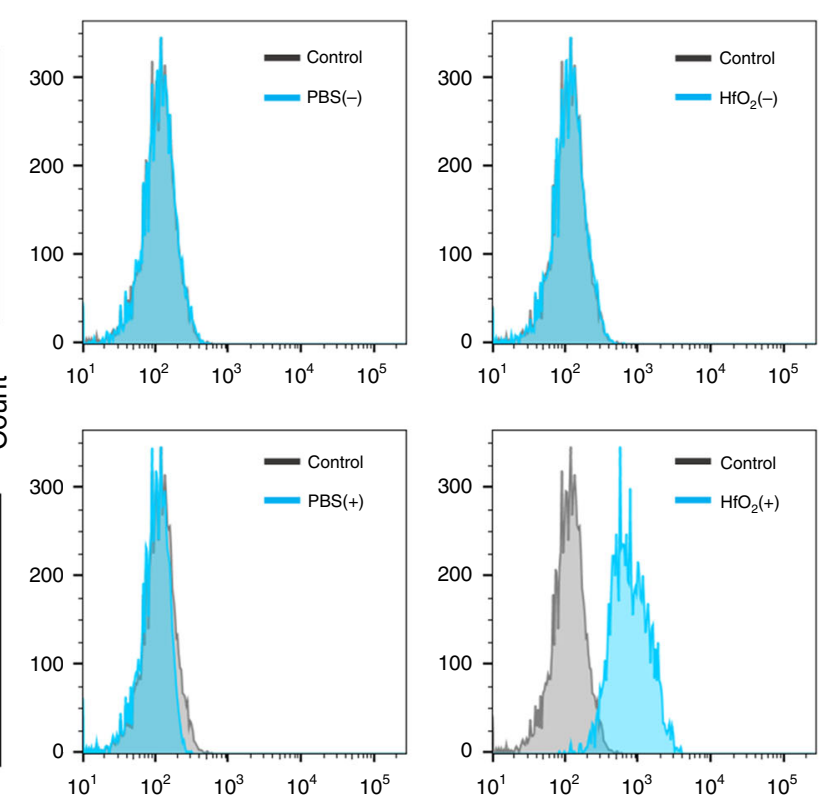
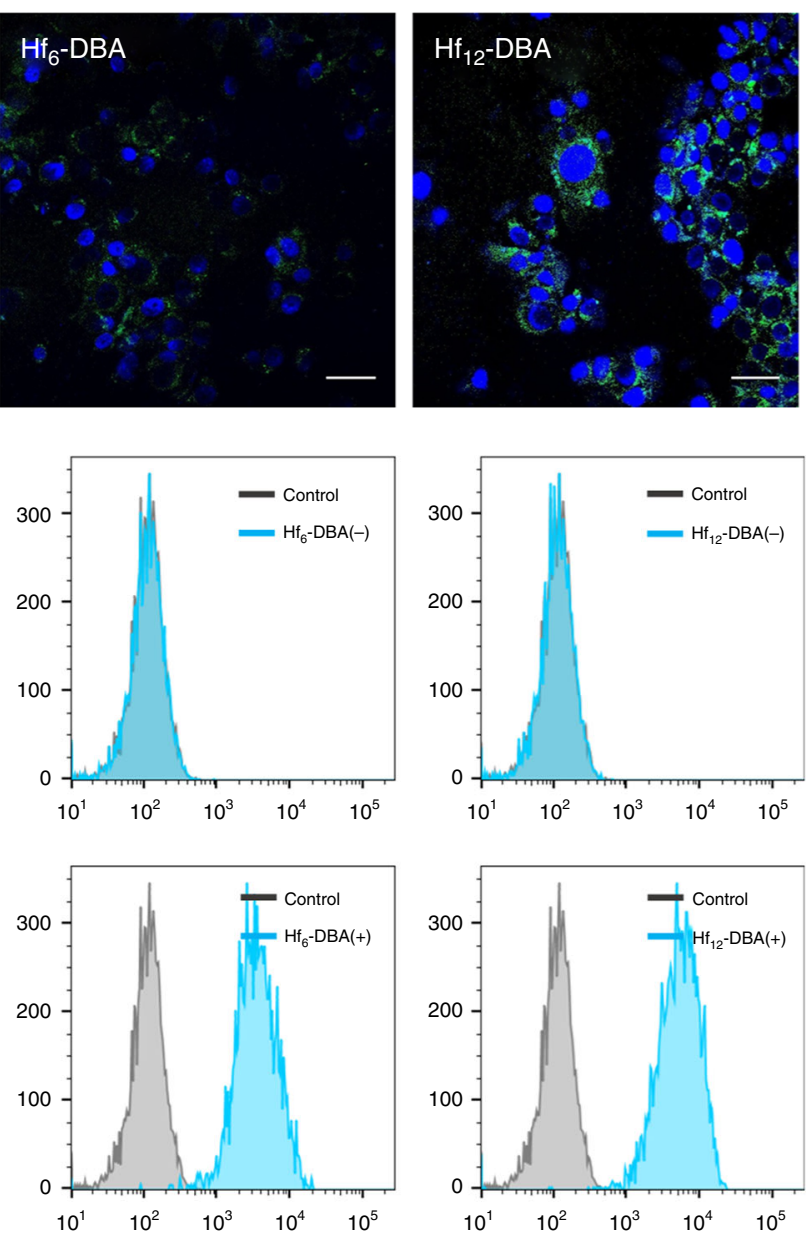

AlexaFluor 488-CRT

C

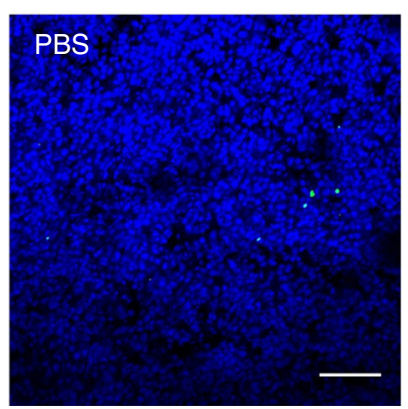

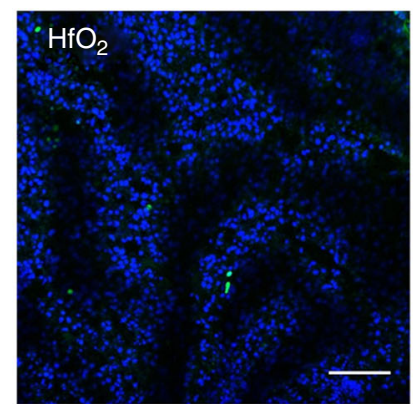
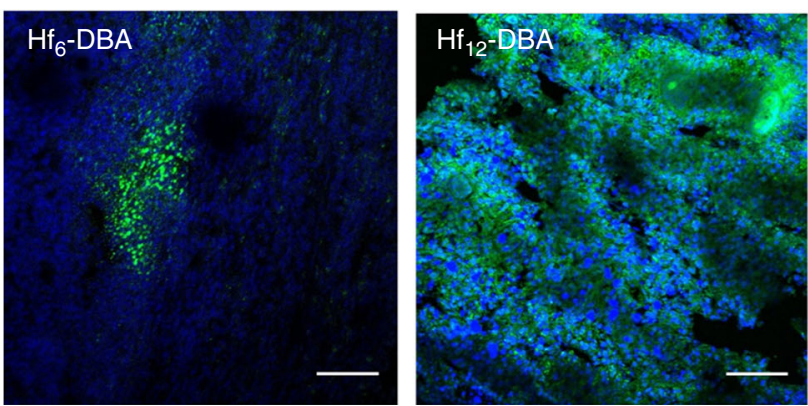

Fig. 5 In vitro and in vivo immunogenic cell death studies. In vitro CRT exposure on the cell surface of $\mathrm{CT}_{26}$ was assessed after incubation with $\mathrm{PBS}, \mathrm{HfO} \mathrm{O}_{2}$ $\mathrm{Hf}_{6}-\mathrm{DBA}$, or $\mathrm{Hf}_{12}-\mathrm{DBA}$ with $\mathrm{X}$-ray irradiation by immunofluorescence microscopy (a) and flow cytometry (b). ( + ) and ( - ) refer to with and without

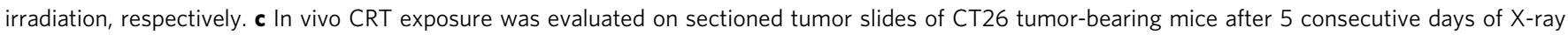
irradiation. Both in vitro confocal images and flow cytometry analyses were obtained with two repetitions. One of two repetitions with similar results is shown. The in vivo confocal images were obtained without repetition. Scale bar $=20 \mu \mathrm{m}(\mathbf{a})$ or $100 \mu \mathrm{m}$ (c)

CRT expression on the cell-surface upon irradiation compared to $\mathrm{Hf}_{6}$-DBA, $\mathrm{HfO}_{2}$, PBS, or without irradiation (Fig. 5b), demonstrating that $\mathrm{Hf}_{12}$-DBA-mediated radiation treatment induced stronger ICD over groups treated with either $\mathrm{Hf}_{6}$-DBA or $\mathrm{HfO}_{2}$ (Supplementary Fig. 23).

We also evaluated CRT expression in CT26 tumor-bearing mice treated with $\mathrm{PBS}, \mathrm{HfO}_{2}, \mathrm{Hf}_{6}$-DBA, or $\mathrm{Hf}_{12}$-DBA and 5 consecutive days of irradiation at $1 \mathrm{~Gy} /$ fraction. The tumors were excised and sectioned for immunostaining. $\mathrm{Hf}_{12}$-DBA-treated tumors showed more green fluorescence (Fig. 5c), indicating that the superior radioenhancement of $\mathrm{Hf}_{12}$-DBA also led to higher CRT expression in vivo.
To further demonstrate the ICD, HMGB1 excretion was examined by the enzyme-linked immunosorbent assay assay in vitro. Compared to groups treated with either $\mathrm{Hf}_{6}$-DBA or $\mathrm{HfO}_{2}$, the higher excretion of HMGB1 from cells treated with $\mathrm{Hf}_{12}$-DBA provided additional evidence for the notion that $\mathrm{Hf}_{12}$ DBA-mediated radiation treatment induced stronger ICD (Supplementary Fig. 24).

In vivo antitumor efficacy of nMOF-mediated RT plus immune checkpoint blockade. We then combined nMOF-mediated RT with checkpoint blockade immunotherapy to extend local 
treatment to systemic cancer management. A bilateral model of CT26 was established to assess the systemic anticancer efficacy of $\mathrm{Hf}_{6}$-DBA-mediated or $\mathrm{Hf}_{12}$-DBA-mediated $\mathrm{RT}$ combined with immune checkpoint blockade. When the primary tumors reached $100-150 \mathrm{~mm}^{3}$ in volume, $\mathrm{nMOF}$ were intratumorally injected to the primary tumors at equivalent doses of $1 \mu \mathrm{mol} \mathrm{Hf}$, followed by daily X-ray irradiation at a dose of $1 \mathrm{~Gy} /$ fraction $(120 \mathrm{kVp}, 20$ $\mathrm{mA}, 2 \mathrm{~mm} \mathrm{Cu}$ filter) for a total of 10 fractions on consecutive days. Seventy-five micrograms of anti-PD-L1 antibody was given every 3 days by intraperitoneal injection.

Combination treatment of nMOFs and anti-PD-L1 antibody regressed the locally irradiated tumors at $10 \mathrm{~Gy}$ of total X-ray dose. Again, the stronger radioenhancer $\mathrm{Hf}_{12}$-DBA outperformed $\mathrm{Hf}_{6}$-DBA in combination therapy (Fig. 4c). More significantly, when combined with an anti-PD-L1 antibody, $\mathrm{Hf}_{12}$-DBA not only produced local regression of irradiated tumors but also shrank distant, non-irradiated tumors. The inhibition of distant tumors by $\mathrm{Hf}_{12}$-DBA-mediated $\mathrm{RT}$ plus checkpoint blockade therapy indicated effective induction of systemic antitumor immune response (Fig. 4d). Histological analysis of the tumors confirmed nMOF-mediated RT caused apoptosis/necrosis in local tumors, while only $\mathrm{Hf}_{12}$-DBA/anti-PD-L1 antibody-treated group showed apoptotic tumor histology with a lower density of tumor cells in the untreated distant tumor (Supplementary Fig. 25). The histologies of major organs did not significantly differ from those of PBS-treated mice, indicating that nMOF-mediated RT with or without checkpoint blockade did not lead to systemic toxicity (Supplementary Fig. 26). This was further confirmed by the steady body weights in all treated mice (Supplementary Fig. 27).

Depletion studies. We further investigated how the therapeutic effects of nMOF-mediated RT plus anti-PD-L1 treatment were affected by immune cells. The anticancer efficacy of combination therapy was assessed in the subcutaneous CT26 model with concurrent depletion of $\mathrm{CD}^{+} \mathrm{T}$ or $\mathrm{CD}^{+} \mathrm{T}$ cells. Mice were intraperitoneally injected with anti-CD4, anti-CD8, or mouse IgG antibodies and then treated with $\mathrm{Hf}_{12}$-DBA and $\mathrm{X}$-ray irradiation combined with an anti-PD-L1 antibody. Both anti-CD4 and antiCD8 antibody-treated groups showed rapid tumor growth after cessation of X-ray treatment, but mouse IgG treatment did not have any effect on tumor growth (Fig. 4e). These results demonstrated that both $\mathrm{CD} 4^{+} \mathrm{T}$ and $\mathrm{CD} 8^{+} \mathrm{T}$ cells played an essential role in the anticancer efficacy of our combination treatment, supporting the rationale of using nMOF-mediated RT to enhance checkpoint blockade cancer immunotherapy.

Tumor challenge studies. To confirm the long-term antitumor immune response, we carried out a tumor challenge study. CT26 tumors were established on the right flanks of mice and treated with $\mathrm{Hf}_{12}$-DBA and X-ray ( $1 \mathrm{~Gy} /$ fraction, 10 fractions in consecutive days). Three out of six mice had their tumors completely eradicated after treatment, affording a cure rate of $50 \%$. Tumors in the other three mice shrank to very small sizes, but regrew beginning days 17,26 , and 32 , respectively, post tumor inoculation. On day 50 post tumor inoculation, approximately 1 month after tumor eradication for the cured mice, the treated mice and naïve control mice were challenged with $2 \times 10^{6}$ CT26 cells on the contralateral, left flank. None of the treated mice developed tumors on the left flank within 21 days (Fig. 4f), but two mice had to be euthanized due to large primary tumor burden. The three cured mice remained tumor-free 60 days after tumor challenge, indicating strong anticancer immune memory effect. In comparison, all mice in the control group consistently developed tumors after injection with $2 \times 10^{6}$ CT26 cells (Fig. 4f).
Antitumor immunity. We then used Enzyme-Linked ImmunoSpot (ELISPOT) and flow cytometry to determine the antitumor immunity of CT26 tumor-bearing mice treated with $\mathrm{Hf}_{12}$-DBAmediated RT plus anti-PD-L1 antibody. The numbers of tumor-antigen-specific cytotoxic $\mathrm{T}$ cells were determined by a interferon- $\gamma$ (IFN- $\gamma$ ) ELISPOT assay. At day 15 after the first treatment, we harvested splenocytes from CT26 tumor-bearing mice and stimulated them with SPSYVYHQF, a tumor-associated antigen, for $42 \mathrm{~h}$. The IFN- $\gamma$ spot-forming cells were then counted by Immunospot Reader. The number of antigen-specific IFN- $\gamma$ producing $\mathrm{T}$ cells was significantly higher in tumor-bearing mice treated with $\mathrm{Hf}_{12}$-DBA plus anti-PD-L1 antibody (100.2 \pm 15.7$)$ than those treated with PBS $(5.3 \pm 2.7)$ or $\mathrm{Hf}_{12}$-DBA $(8.2 \pm 6.1$, Fig. 6a). These results suggest that $\mathrm{Hf}_{12}-\mathrm{DBA}$ with $\mathrm{X}$-ray irradiation plus anti-PD-L1 antibody effectively generates tumorspecific T cell response.

We further profiled infiltrating leukocytes in both the primary and distant tumors. There was no significant difference between PBS with or without X-ray irradiation, demonstrating that lowdose X-ray irradiation did not influence the immunological environment of tumors. The $\mathrm{Hf}_{12}$-DBA with antibody group showed significant increase of tumor-infiltrating $\mathrm{CD}^{+}{ }^{+} \mathrm{T}$ cells and $\mathrm{CD}^{+} \mathrm{T}$ cells in both the primary tumors and the distant tumors (Fig. 6c, d). Specifically, for the primary tumor, the percentage of $\mathrm{CD} 8^{+} \mathrm{T}$ cells in the total tumor cells significantly increased in both $\mathrm{Hf}_{12}$-DBA-mediated RT $(2.92 \pm 1.58 \%)$ and $\mathrm{Hf}_{12}$-DBA-mediated RT plus anti-PD-L1-treated groups $(2.42 \pm$ $1.31 \%)$ compared to the PBS control group $(0.67 \pm 0.40 \%)$. For the distant tumor, the percentage of $\mathrm{CD}^{+} \mathrm{T}$ cells in the total tumor cells increased in $\mathrm{Hf}_{12}$-DBA-mediated RT plus anti-PD-L1 treatment group $(2.04 \pm 1.24 \%)$ compared to $\mathrm{Hf}_{12}$-DBA-mediated RT group $(1.21 \pm 0.48 \%)$ and PBS control group $(1.20 \pm 0.20 \%)$ (Fig. 6c). The significant increase of infiltrating $\mathrm{CD}^{+} \mathrm{T}$ cells, which was further confirmed by immunofluorescence imaging (Supplementary Method 4) as shown in Supplementary Fig. 28, likely induced the abscopal effect. The $\mathrm{Hf}_{12}$-DBA with antibody group showed significant increase of tumor-infiltrating $B$ cells (Supplementary Fig. 29) as well as $\mathrm{CD} 45^{+}$leukocyte cells (Fig. 6b) in the primary tumors but not in the distant tumors. No significant difference was observed across the different treatment groups in the amount of $\mathrm{CD} 4^{+}$, regulatory, and $\mathrm{CD} 8^{+} \mathrm{T}$ cells in the lymph nodes (Supplementary Fig. 30).

In immunotherapy, dendritic cells can be recruited to the tumor sites and then present antigens to $\mathrm{T}$ cells after migration to the lymph nodes. $\mathrm{Hf}_{12}$-DBA-mediated $\mathrm{RT}$ groups significantly increased the percentages of dendritic cells in primary tumors (Fig. 6e). We also found a significant increase of NK cells in both primary and distant tumors treated with $\mathrm{Hf}_{12}$-DBA-mediated RT and anti-PD-L1 antibody (Fig. 6f). These results suggested that the combination of nMOF-mediated RT and PD-L1 checkpoint blockade therapy not only augmented tumor-specific adaptive response but also induced innate immune response in tumors.

\section{Discussion}

A major challenge in RT is to maximize the therapeutic effect while minimizing deleterious effects on the surrounding healthy tissues. The therapeutic ratio of RT can be enlarged with radioenhancers that can effectively increase differential radiation absorption between healthy and tumor tissues. Although NPs of high- $Z$ elements, such as $\mathrm{HfO}_{2}$ and $\mathrm{Au}$ NPs, have been extensively studied for this purpose, no NP-based radioenhancer has been approved by the Food and Drug Administration for clinical use. In the study of Au NPs, it was found that ROS generation is inversely proportional to the particle diameter, indicating that larger specific surface areas may be an important design 

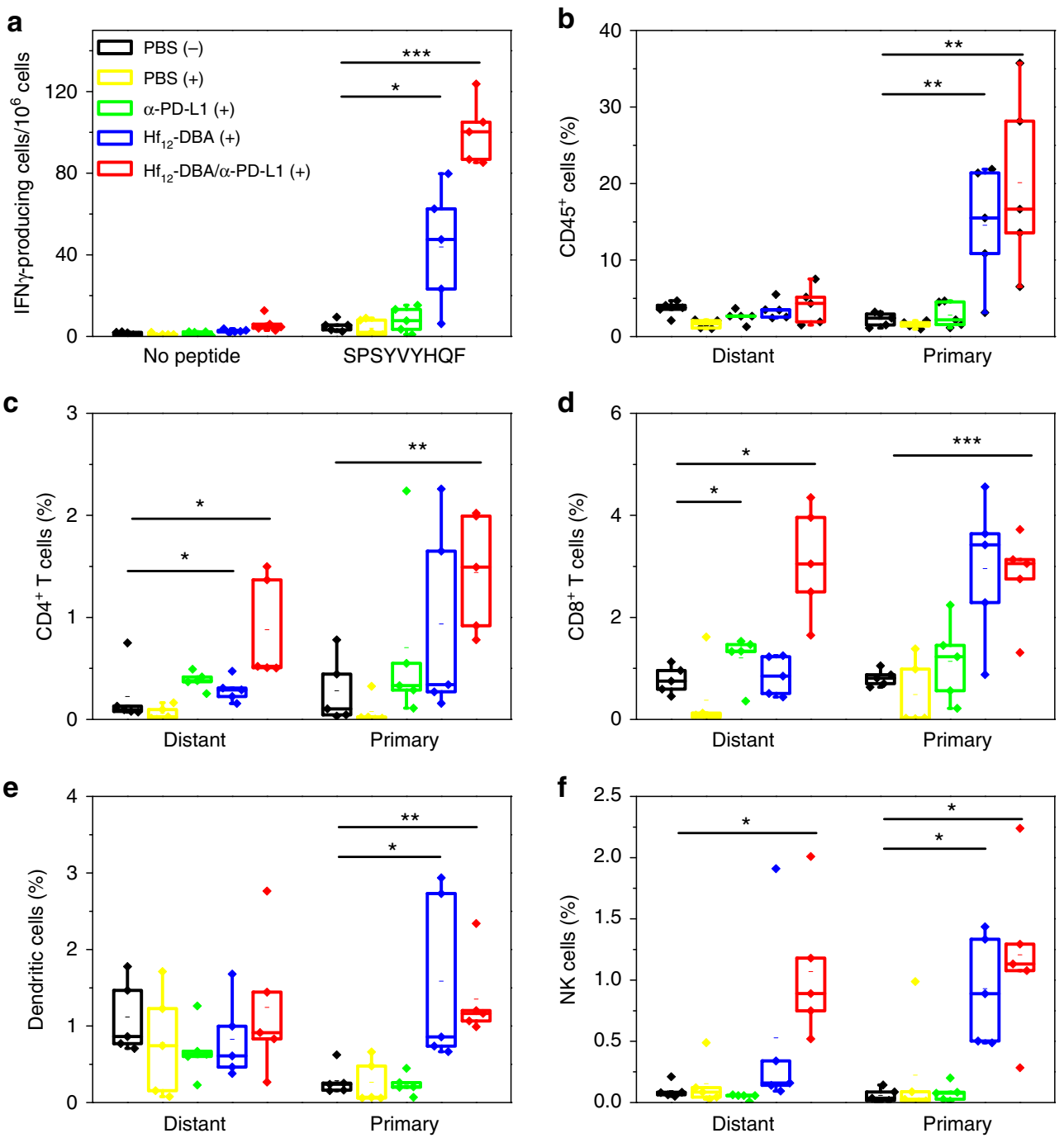

Fig. 6 Tumor-specific immune responses. Bilateral tumor models of CT26 were established and treated as described in Fig. 4. Ten days after the first treatment, the splenocytes were harvested and stimulated with $10 \mu \mathrm{g} / \mathrm{mL}$ SPSYVYHQF peptide for $42 \mathrm{~h}$. ELISPOT assay was performed to detect IFN- $\gamma$ producing $\mathrm{T}$ cells (a). The primary (right) and distant (left) tumors were collected for flow cytometry analysis and the percentage of tumor-infiltrating CD $45^{+}$cells $(\mathbf{b}), \mathrm{CD} 4^{+} \mathrm{T}$ cells $(\mathbf{c}), \mathrm{CD} 8^{+} \mathrm{T}$ cells $(\mathbf{d})$, dendritic cells (e), and NK cells (f) with respect to the total tumor of cells treated with PBS dark control, PBS, anti-PD-L1 antibody, $\mathrm{Hf}_{12}-\mathrm{DBA}$, or $\mathrm{Hf}_{12}$-DBA plus anti-PD-L1 antibody with X-ray irradiation. $n=5$. ${ }^{\star} P<0.05$ from control, ${ }^{\star \star} P<0.01$ from control, and ${ }^{\star \star \star} P<0.001$ from control by $t$ test. Central lines, bounds of box and whiskers represent mean values, $25 \%$ to $75 \%$ of the range of data and 1.5 fold of interquartile range away from outliers, respectively

parameter. ${ }^{41}$ We therefore hypothesize that Hf-based nMOFs, $\mathrm{Hf}_{6}$-DBA and $\mathrm{Hf}_{12}$-DBA, which possess both high- $\mathrm{Z}$ elements and high specific surface areas, can be ideal candidates for radiation enhancement (Fig. 2b). Moreover, the porous structure of MOFs can facilitate fast diffusion of ROS, which have very short lifetimes typically on the order of $10^{-7}$ to $10^{-4} \mathrm{~s}$.

Compared to incident X-rays, secondary photons generated from the enhanced photoelectric and/or Compton effects have lower energies and are more likely to interact with the radioenhancers. However, in the case of solid NPs, the secondary photons are only generated on the surface of NPs and cannot be effectively used since the photons are randomly scattered in all directions and have low probability to encounter other NPs. In contrast, the periodic structure of nMOFs may allow for effective use of secondary photons and electrons. Each Hf SBU is surrounded by other $\mathrm{Hf}$ clusters extended in all directions with intercluster distance typically shorter than $2 \mathrm{~nm}$. As a result, there is a higher probability for the secondary photons generated inside the
MOFs to interact with other metal clusters, setting off a chain reaction to enhance the overall efficacy of RT.

In order to examine the efficacy of nMOFs with high- $Z$ elements for RT, we synthesized two Hf-based nMOFs of $<100 \mathrm{~nm}$ in sizes. As a control, ultra-small solid $\mathrm{HfO}_{2} \mathrm{NPs}$ with a diameter of $\sim 10 \mathrm{~nm}$ were also synthesized. Normalized to the same amount of $\mathrm{Hf}$, both $\mathrm{Hf}_{6}$-DBA and $\mathrm{Hf}_{12}$-DBA outperformed $\mathrm{HfO}_{2} \mathrm{NPs}$ in radioenhancement, evidenced by in vitro and in vivo results. The enhanced $\mathrm{RT}$ effect of $\mathrm{Hf}_{6}$-DBA and $\mathrm{Hf}_{12}$-DBA may be attributed to their large specific surface areas of $\mathrm{Hf}_{6}$ or $\mathrm{Hf}_{12}$ clusters and porous framework structures. Interestingly, $\mathrm{Hf}_{12}$-DBA is a better radioenhancer than $\mathrm{Hf}_{6}$-DBA, likely due to more efficient X-ray absorption of $\mathrm{Hf}_{12}$ clusters over $\mathrm{Hf}_{6}$ clusters, leading to increased generation of hydroxyl radicals as evidenced by APF assay. To support this hypothesis, we synthesized two anthracene-based Hf-nMOFs, $\mathrm{Hf}_{6}$-DBAn and $\mathrm{Hf}_{12}$-DBAn, which are structurally similar to $\mathrm{Hf}_{6}$-DBA and $\mathrm{Hf}_{12}$-DBA, respectively, and studied their radioluminescence. Upon X-ray irradiation, Hf clusters absorb 
energy and subsequently transfer the energy to the anthracenebased ligands to generate luminescence. The luminescence intensity can then be used as a measure of X-ray absorption efficiency. Normalized to the same amount of $\mathrm{Hf}, \mathrm{Hf}_{12}$-DBAn has fewer DBAn ligands (0.75 DBAn per $\mathrm{Hf}$ ) than $\mathrm{Hf}_{6}$-DBAn (1 DBAn per Hf), but afforded much higher X-ray-induced luminescence intensity. The radioluminescence result supports the hypothesis that $\mathrm{Hf}_{12}$ clusters absorb X-ray more efficiently than $\mathrm{Hf}_{6}$ clusters.

As a local therapy, hypofractionated RT with relatively high daily doses of 5-10 Gy and a shortened treatment duration can also trigger a local immune response by releasing immunostimulating signals to increase $\mathrm{T}$ cell infiltration to the tumor. ${ }^{42-45}$ Over one hundred of clinical trials are ongoing to exploit the synergy between hypofractionated RT and immune checkpoint blockade. ${ }^{17,46-48}$ However, the immunostimulatory effects of hypofractionated RT are achieved at the expense of damaging side effects on surrounding tissues. ${ }^{49}$ Furthermore, the dosing schedule of hypofractionated RT is not synchronous with checkpoint blockade immunotherapy. ${ }^{50}$ We hypothesize that effective radioenhancers can not only enhance the localized therapeutic effects of RT but can also lead to immunostimulatory tumor microenvironments that can potentiate checkpoint blockade immunotherapy. In this study, we showed that $\mathrm{Hf}_{12}$ DBA not only exhibited superior radioenhancing effects to improve regression of irradiated tumors as local therapy but also regressed distant, un-irradiated tumors when used in combination with an anti-PD-L1 antibody (Fig. 7). The combination of nMOF-mediated RT with an anti-PD-L1 antibody thus effectively

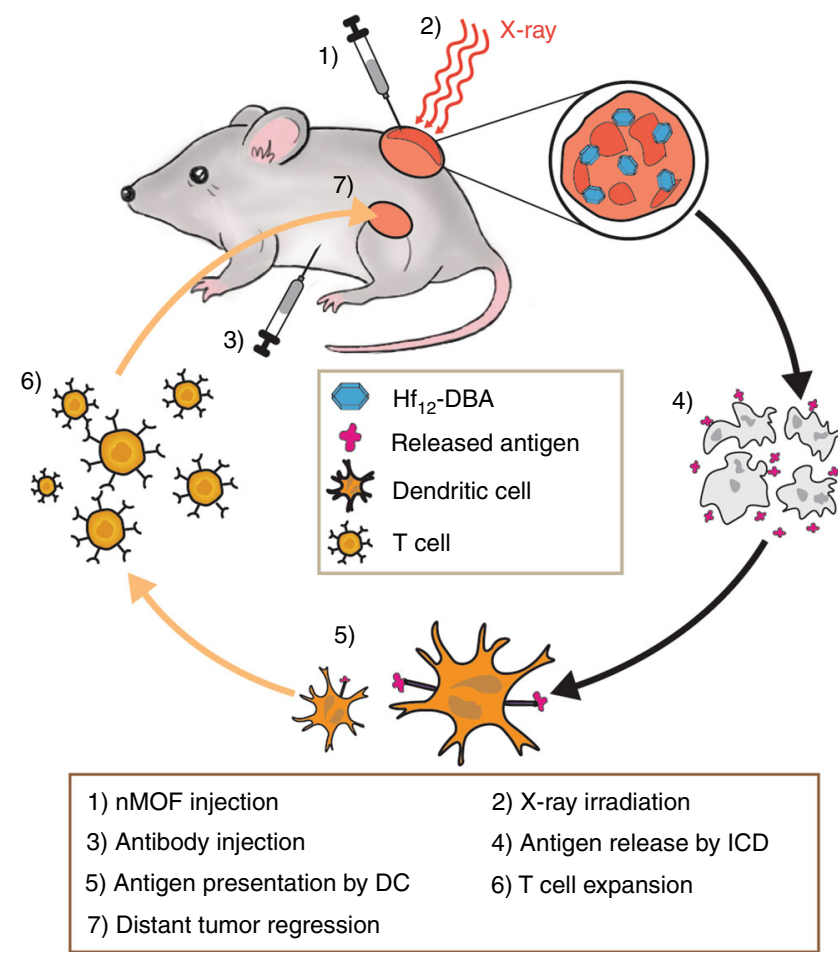

Fig. 7 Abscopal effect of nMOF-mediated RT and immune checkpoint blockade using fractionated X-rays. nMOF was intratumorally injected into the primary tumors of mice bearing bilateral subcutaneous tumors. nMOFmediated RT destroyed the irradiated tumors, caused immunogenic cell death, and released tumor antigen. Injected anti-PD-L1 antibody overcame the suppressive tumor microenvironment by targeting PD-1/PD-L1 axis. The combination of nMOF-mediated RT and anti-PD-L1 checkpoint blockade led to the effective $T$ cell expansion and tumor infiltration, which effectively suppressed/eradicated the distant tumors extended the local therapeutic effects of RT to distant tumors via abscopal effects, affording a potent systemic antitumor treatment.

PD-1 is a cell-surface co-inhibitory receptor expressed on T cells, B cells, monocytes, and NK cells with two known ligands, PD-L1 and PD-L2. ${ }^{51}$ PD-L1 is upregulated on tumor cells and other cells in the tumor microenvironment. Blockade of the PD1/PD-L1 axis using anti-PD-1 or anti-PD-L1 antibodies can restore $\mathrm{T}$ cell activity against tumor cells, providing potent antitumor efficacy. Infiltrating T cells are essential for PD-L1 blockade therapy to be effective but are only found in immunogenic tumor microenvironments. As a result, checkpoint blockade immunotherapy is only effective in patients whose tumors are immunogenic, leading to the low rate of durable responses in many cancers. Our work shows that nMOF-mediated RT provides an efficient way to induce immunogenicity in the tumor microenvironment and enhance antitumor immunity of anti-PDL1. We have elucidated the mechanisms behind nMOF-mediated radioenhancement and the immunotherapeutic effect of combination treatment with $\mathrm{Hf}_{12}$-DBA and irradiation plus an anti-PDL1 antibody. The numbers of antigen-specific IFN- $\gamma$-producing $\mathrm{T}$ cells and $\mathrm{CD}^{+} \mathrm{T}$ cells significantly increased in distant, unirradiated tumors to lead to tumor rejection/regression. It is possible that nMOF-mediated RT can be combined with other forms of immunotherapies such as STING agonists or CpG oligonucleotides to lead to systemic antitumor immunity.

In summary, we have developed Hf-based nMOFs as effective radioenhancers for low-dose X-ray $\mathrm{RT}$. The combination of nMOF-mediated RT and PD-L1 checkpoint blockade extended the local therapeutic effects of RT to distant tumors via systemic antitumor immunity. With the ability to rationally design and systematically tune the compositions and structures of nMOFs, we expect that even more powerful nMOF-based radioenhancers will become available to drastically enhance the efficacy of RT without incurring deliberating side effects and to significantly potentiate checkpoint blockade immunotherapy for the treatment of non-immunogenic tumors.

\begin{abstract}
Methods
Cell lines and animals. Human head and neck cancer cells, SQ20B and JSQ3, and murine breast cancer cells, TUBO and 4T1, were kindly provided by Dr. Stephen J. Kron at the University of Chicago. The murine colon adenocarcinoma cell, CT26, and the human cervical cancer cell, HeLa, were purchased from the American Type Culture Collection (Rockville, MD, USA). TUBO and CT26 cells were cultured in Roswell Park Memorial Institute (RPMI) 1640 medium (GE Healthcare, USA) supplemented with $10 \%$ fetal bovine serum (FBS, VWR, USA). 4T1 and HeLa cells were cultured in Dulbecco's modified Eagle's medium (DMEM) (GE Healthcare, USA) supplemented with 10\% FBS. SQ20B and JSQ3 cells were cultured in DMEM and Ham's F-12 nutrient mixture (DME/F12) medium (GE Healthcare, USA) supplemented with $20 \%$ FBS. All medium was further supplemented with $100 \mathrm{U} /$ $\mathrm{mL}$ penicillin $\mathrm{G}$ sodium and $100 \mu \mathrm{g} / \mathrm{mL}$ streptomycin sulfate. Cells were cultured in a humidified atmosphere containing $5 \% \mathrm{CO}_{2}$ at $37^{\circ} \mathrm{C}$. Mycoplasma was tested before use by MycoAlert Detection Kit (Lonza Nottingham Ltd.) BALB/c mice (6-8 weeks) were obtained from Harlan-Envigo Laboratories Inc. (USA). The study protocol was reviewed and approved by the Institutional Animal Care and Use Committee (IACUC) at the University of Chicago.
\end{abstract}

Synthesis of $\mathbf{H f}_{\mathbf{6}}$-DBA and $\mathbf{H f}_{\mathbf{6}}$-DBAn $\mathbf{n M O F s . ~ T o ~ a ~} 1$ dram glass vial was added $0.5 \mathrm{~mL}$ of $\mathrm{HfCl}_{4}$ solution $(2.0 \mathrm{mg} / \mathrm{mL}$ in dimethylformamide (DMF)), $0.5 \mathrm{~mL}$ of the 2,5 -di( $p$-benzoato aniline $\left(\mathrm{H}_{2} \mathrm{DBA}\right)$ solution $(2.0 \mathrm{mg} / \mathrm{mL}$ in $\mathrm{DMF})$ or 2,5 - $\mathrm{di}(p$ benzoato)anthracene $\left(\mathrm{H}_{2} \mathrm{DBAn}\right)$ solution $(2.5 \mathrm{mg} / \mathrm{mL}$ in $\mathrm{DMF})$ and $0.5 \mu \mathrm{L}$ of trifluoroacetic acid. The reaction mixture was kept in a $60{ }^{\circ} \mathrm{C}$ oven for $72 \mathrm{~h}$. The white precipitate was collected by centrifugation and washed with DMF, $1 \%$ trimethylamine/ethanol solution, and ethanol.

Synthesis of $\mathbf{H f}_{\mathbf{1 2}}$-DBA and $\mathbf{H f}_{\mathbf{1 2}}$-DBAn $\mathbf{n M O F s . ~ T o ~ a ~} 1$ dram glass vial was added $0.5 \mathrm{~mL}$ of $\mathrm{HfCl}_{4}$ solution $\left(1.6 \mathrm{mg} / \mathrm{mL}\right.$ in DMF), $0.5 \mathrm{~mL}$ of the $\mathrm{H}_{2} \mathrm{DBA}$ solution (1.6 $\mathrm{mg} / \mathrm{mL}$ in DMF) or $\mathrm{H}_{2}$ DBAn solution ( $2 \mathrm{mg} / \mathrm{mL}$ in DMF), $75 \mu \mathrm{L}$ of acetic acid, and $5 \mu \mathrm{L}$ of water. The reaction mixture was kept in an $80^{\circ} \mathrm{C}$ oven for $72 \mathrm{~h}$. The white precipitate was collected by centrifugation and washed with DMF, a $1 \%$ trimethylamine/ethanol solution, and ethanol. 
Synthesis of $\mathbf{H f O}_{\mathbf{2}} \mathbf{N P s}$. $\mathrm{HfO}_{2} \mathrm{NPs}$ were synthesized according to the reported protocol..$^{52}$ To a $20 \mathrm{~mL}$ Teflon cup was added $15 \mathrm{~mL}$ of $\mathrm{HfCl}_{4}$ solution $(10 \mathrm{mg} / \mathrm{mL}$ in benzyl alcohol), which was sealed in a steel autoclave and heated to $200^{\circ} \mathrm{C}$ for $48 \mathrm{~h}$. The white precipitate was collected by centrifugation and washed with ethanol.

Radioluminescence measurements of $\mathbf{H f}_{\mathbf{1 2}}$ - - $\mathrm{BAAn}$ and $\mathbf{H f}_{\mathbf{6}}$-DBAn. $\mathrm{Hf}_{12}$-DBAn and $\mathrm{Hf}_{6}$-DBAn were suspended in ethanol at an $\mathrm{Hf}$ concentration of $1 \mathrm{mM}$, degassed, and refilled with nitrogen gas. The solutions were transferred to 1 dram vials for X-ray irradiation with a maximum dose rate of $2.93 \mathrm{~Gy} / \mathrm{min}$. X-ray luminescence measurements were acquired with a small animal irradiator (X-RAD $225 \mathrm{Cx}$ by Precision X-ray) through a $2 \mathrm{~mm}$ aluminum filter. The radioluminescence was detected using a cooled CoolSNAP HQ2 CCD camera (Photometrics, USA) equipped with a DX Micro-NIKKOR f/2.8 macro lens (Nikon, Japan). Samples were tested at a voltage of $70 \mathrm{kVp}$ and current values ranging from $5,10,20,30$ to $40 \mathrm{~mA}$ for $30 \mathrm{~s}$. Radioluminescence intensities were processed by ImageJ with background subtraction.

Detection of hydroxyl radical produced by irradiation. $\mathrm{HfO}_{2}, \mathrm{Hf}_{6}$-DBA, and $\mathrm{Hf}_{12}$-DBA were suspended in water at equivalent $\mathrm{Hf}$ concentrations of $20 \mu \mathrm{M}$ in the presence of $5 \mu \mathrm{M}$ APF. A water solution of $5 \mu \mathrm{M}$ APF was used as background. One hundred microliters of each suspension was added to a 96-well plate and then irradiated with $0,1,2,3,5$, or 10 Gy X-ray (Philips RT250 X-ray generator, Philips, USA, $250 \mathrm{KVp}, 15 \mathrm{~mA}, 1 \mathrm{~mm} \mathrm{Cu}$ filter). The fluorescence signal was immediately collected with a Xenogen IVIS 200 imaging system.

Clonogenic assay. The clonogenic assay was performed according to a modified protocoll ${ }^{53}$ CT26 cells were cultured in a 6-well plate overnight and incubated with particles at an Hf concentration of $20 \mu \mathrm{M}$ for $4 \mathrm{~h}$ followed by irradiation with 0,1 , $2,4,8$, and $16 \mathrm{~Gy} \mathrm{X}$-ray $\left(250 \mathrm{kVp}, 15 \mathrm{~mA}, 1 \mathrm{~mm} \mathrm{Cu}\right.$ filter) or $\gamma$-ray $\left({ }^{60} \mathrm{Co}\right.$ source, Atomic Energy Canada Limited, Canada). Cells were trypsinized and counted immediately. One hundred to one thousand cells were seeded in a 6-well plate and cultured with $2 \mathrm{~mL}$ medium for 10-20 days. Once colony formation was observed, the culture medium was discarded. The plates were rinsed twice with PBS, and then stained with $500 \mu \mathrm{L}$ of $0.5 \% \mathrm{w} / \mathrm{v}$ crystal violet in $50 \%$ methanol $/ \mathrm{H}_{2} \mathrm{O}$. The wells were rinsed with water and the colonies were counted manually.

Apoptosis/necrosis. CT26 cells were cultured in a 6-well plate overnight and incubated with particles at an $\mathrm{Hf}$ concentration of $20 \mu \mathrm{M}$ for $4 \mathrm{~h}$ followed by irradiation with 0 or $2 \mathrm{~Gy}$ X-ray $(250 \mathrm{kVp}, 15 \mathrm{~mA}, 1 \mathrm{~mm} \mathrm{Cu}$ filter). After $24 \mathrm{~h}$, the cells were stained according to the AlexaFluor 488 Annexin V/Dead Cell Apoptosis Kit (Life Technology, USA) and quantified by flow cytometry.

DNA damage. CT26 cells were cultured in a 6-well plate overnight and incubated with particles at an $\mathrm{Hf}$ concentration of $20 \mu \mathrm{M}$ for $4 \mathrm{~h}$ followed by irradiation at 0 and 2 Gy X-ray $(250 \mathrm{kVp}, 15 \mathrm{~mA}, 1 \mathrm{~mm}$ Cu filter). Cells were stained immediately with the HCS DNA Damage Kit (Life Technology, USA) for CLSM (FV1000, Olympus, Japan) and flow cytometry. ImageJ was used to quantify the number of cells with foci and number of intranuclear foci.

Immunogenic cell death. CT26 cells were cultured in a 6-well plate overnight and incubated with particles at an $\mathrm{Hf}$ concentration of $20 \mu \mathrm{M}$ for $4 \mathrm{~h}$ followed by irradiation with 0 or $2 \mathrm{~Gy}$ X-ray $(250 \mathrm{kVp}, 15 \mathrm{~mA}, 1 \mathrm{~mm} \mathrm{Cu}$ filter). After incubation for $4 \mathrm{~h}$, the cells were washed three times with PBS, fixed with $4 \%$ paraformaldehyde, incubated with AlexaFluor 488-CRT (Enzo Life Sciences, USA) with 1:100 dilution for $2 \mathrm{~h}$, stained with 4',6-diamidino-2-phenylindole, and observed by CLSM. Treated cells were incubated for $4 \mathrm{~h}$, collected, incubated with AlexaFluor 488-CRT antibody for $2 \mathrm{~h}$, and then stained with propidium iodide (PI) for analysis by flow cytometry (LSRFortessa, BD, USA).

In vivo anticancer efficacy. A bilateral model was established by subcutaneously inoculating $2 \times 10^{6}$ and $1 \times 10^{6} \mathrm{CT} 26$ cells onto the right and left flanks of BALB/c mice for respective primary and secondary tumors. When the primary tumors reached $100-150 \mathrm{~mm}^{3}$ in volume, mice were injected intratumorally with nMOFs at a dose of $1 \mu \mathrm{mol} \mathrm{Hf}$ or PBS. Twelve hours after injection, mice were anesthetized with $2 \%(\mathrm{v} / \mathrm{v})$ isoflurane and the primary tumors were irradiated with $1 \mathrm{~Gy} \mathrm{X}$-ray/ fraction ( $120 \mathrm{kVp}, 20 \mathrm{~mA}, 2 \mathrm{~mm}$ Cu filter) for a total of 10 daily fractions. Anti-PDL1 antibody was given every 3 days by intraperitoneal injection at a dose of $75 \mu \mathrm{g} /$ mouse. The tumor sizes were measured daily with a caliper where tumor volume equals (width ${ }^{2} \times$ length)/2. Mice treated with $\mathrm{Hf}_{6}$-DBA and $\mathrm{Hf}_{12}$-DBA were sacrificed on day 30 and mice treated with PBS or anti-PD-L1 antibody alone were sacrificed on day 21 . Each mouse was weighed daily to evaluate toxicity.

T cell depletion. The bilateral subcutaneous model was established as for the in vivo anticancer efficacy. When the primary tumors reached $100-150 \mathrm{~mm}^{3}$ in volume, mice were injected intratumorally with nMOFs at a dose of $1 \mu \mathrm{mol} \mathrm{Hf}$ or PBS. Anti-CD4 (GK1.5, BioXCell, USA), anti-CD8 (OKT-8, BioXCell, USA), or mouse IgG (C1.18.4, BioXCell, USA) antibodies were intraperitoneally injected into the mice $(200 \mu \mathrm{g} /$ mouse per injection) on days 0 and 5 after the first treatment. Ten hours post injection, mice were anesthetized with $2 \%(\mathrm{v} / \mathrm{v})$ isoflurane, and tumors were irradiated with image-guided X-ray at $225 \mathrm{kVp}$ and $13 \mathrm{~mA}$ with a $0.3 \mathrm{~mm} \mathrm{Cu}$ filter. To evaluate the therapeutic efficacy, the tumor growth and body weight were monitored daily.

Tumor challenge studies. CT26 cells $\left(2 \times 10^{6}\right)$ were inoculated subcutaneously onto the right flank of BALB/c mice. When the tumors reached $100-150 \mathrm{~mm}^{3}$ in volume, mice were injected intratumorally with nMOFs at a dose of $1 \mu \mathrm{mol} \mathrm{Hf}$ or PBS. Twelve hours after injection, mice were anesthetized with $2 \%(\mathrm{v} / \mathrm{v})$ isoflurane and the primary tumors were irradiated with $1 \mathrm{~Gy}$ X-ray/fraction $(120 \mathrm{kVp}, 20 \mathrm{~mA}$, $2 \mathrm{~mm} \mathrm{Cu}$ filter) for a total of 10 daily fractions. On day 50 post inoculation, mice were challenged with $2 \times 10^{6}$ cells on the contralateral flank. Healthy mice were simultaneously inoculated as control. The mice were sacrificed when the tumors of the control mice reached $2 \mathrm{~cm}^{3}$. Statistical analysis was performed using the logrank Kaplan-Meier estimation.

ELISpot assay. ELISpot assay (Mouse IFN- $\gamma$ ELISpot Ready-SET-Go!; Cat. No. 887384-88; eBioscience) was used to determine tumor-specific immune responses to IFN- $\gamma$ in vitro. A Millipore Multiscreen HTS-IP plate was coated with anti-mouse IFN- $\gamma$ capture antibody at $4{ }^{\circ} \mathrm{C}$ overnight. Single-cell suspensions of splenocytes were obtained from CT26 tumor-bearing mice and seeded onto the antibodycoated plate at a concentration of $2 \times 10^{5}$ cells/well. Cells were incubated with or without SPSYVYHQF stimulation $(10 \mu \mathrm{g} / \mathrm{ml}$; in purity $>95 \%$; PEPTIDE 2.0$)$ for 42 $\mathrm{h}$ at $37^{\circ} \mathrm{C}$ and then discarded. The plate was then incubated with biotin-conjugated anti-IFN- $\gamma$ detection antibody at room temperature (r.t.) for $2 \mathrm{~h}$, followed by incubation with Avidin-HRP at r.t. for $2 \mathrm{~h}$. A solution of 3-amino-9-ethylcarbazole (Sigma, Cat. No. AEC101) was added as a substrate for cytokine spot detection. Spots were imaged and quantified with a CTL ImmunoSpot Analyzer (Cellular Technology Ltd, USA).

Lymphocyte profiling. Tumors were harvested, and then treated with $1 \mathrm{mg} / \mathrm{ml}$ collagenase I (Gibco, USA) for $1 \mathrm{~h}$ at $37^{\circ} \mathrm{C}$. Cells were filtered through nylon mesh filters with a size of $40 \mu \mathrm{m}$ and washed with PBS. Tumor-draining lymph nodes were collected and directly ground through the cell strainers. The single-cell suspension was incubated with anti-CD16/32 (clone 93) to reduce nonspecific binding to FcRs. Cells were further stained with the following fluorochrome-conjugated antibodies: CD45 (30-F11), CD3ع (145-2C11), CD4 (GK1.5), CD8 (53-6.7), Foxp3 (FJK-16s), CD25 (PC61.5), Nkp46 (29A1.4), F4/80 (BM8), B220 (RA3-6B2), and PI (all from eBioscience). Antibodies were used at a dilution of 1:200. Representative gating strategies for different immune cells are shown in Supplementary Fig. 31. LSRFortessa (BD Biosciences) was used for cell acquisition and data analysis was carried out with the FlowJo software (Tree Star, Ashland, OR, USA).

Data availability. The authors declare that all the data supporting the findings of this study are available within the article and its Supplementary Information files or from the corresponding author upon reasonable request.

Received: 17 January 2018 Accepted: 17 May 2018

Published online: 15 June 2018

\section{References}

1. Mellman, I., Coukos, G. \& Dranoff, G. Cancer immunotherapy comes of age. Nature 480, 480-489 (2011).

2. Rosenberg, S. A., Yang, J. C. \& Restifo, N. P. Cancer immunotherapy: moving beyond current vaccines. Nat. Med. 10, 909-915 (2004).

3. Dunn, G. P., Bruce, A. T., Ikeda, H., Old, L. J. \& Schreiber, R. D. Cancer immunoediting: from immunosurveillance to tumor escape. Nat. Immunol. 3, 991-998 (2002).

4. Smyth, M. J., Godfrey, D. I. \& Trapani, J. A. A fresh look at tumor immunosurveillance and immunotherapy. Nat. Immunol. 2, 293-299 (2001).

5. Grivennikov, S. I., Greten, F. R. \& Karin, M. Immunity, inflammation, and cancer. Cell 140, 883-899 (2010).

6. Sharma, P. \& Allison, J. P. The future of immune checkpoint therapy. Science 348, 56-61 (2015).

7. Francisco, L. M., Sage, P. T. \& Sharpe, A. H. The PD-1 pathway in tolerance and autoimmunity. Immunol. Rev. 236, 219-242 (2010).

8. Errico, A. Immunotherapy: PD-1-PD-L1 axis: efficient checkpoint blockade against cancer. Nat. Rev. Clin. Oncol. 12, 63-63 (2015).

9. Le, D. T. et al. PD-1 blockade in tumors with mismatch-repair deficiency. N. Engl. J. Med. 372, 2509-2520 (2015). 
10. Tumeh, P. C. et al. PD-1 blockade induces responses by inhibiting adaptive immune resistance. Nature 515, 568-571 (2014).

11. Rizvi, N. A. et al. Mutational landscape determines sensitivity to PD-1 blockade in non-small cell lung cancer. Science 348, 124-128 (2015).

12. Shahabi, V., Postow, M. A., Tuck, D. \& Wolchok, J. D. Immune-priming of the tumor microenvironment by radiotherapy: rationale for combination with immunotherapy to improve anticancer efficacy. Am. J. Clin. Oncol. 38, 90-97 (2015).

13. Gajewski, T. F. et al. Cancer immunotherapy strategies based on overcoming barriers within the tumor microenvironment. Curr. Opin. Immunol. 25, 268-276 (2013).

14. Joyce, J. A. \& Fearon, D. T. T cell exclusion, immune privilege, and the tumor microenvironment. Science 348, 74-80 (2015).

15. Ma, Y. et al. Seminars in Immunology 113-124 (Elsevier, Amsterdam, 2010).

16. Gajewski, T. F., Schreiber, H. \& Fu, Y.-X. Innate and adaptive immune cells in the tumor microenvironment. Nat. Immunol. 14, 1014-1022 (2013).

17. Schaue, D. A century of radiation therapy and adaptive immunity. Front. Immunol. 8, 431 (2017).

18. Apetoh, L. et al. Toll-like receptor 4-dependent contribution of the immune system to anticancer chemotherapy and radiotherapy. Nat. Med. 13, 1050-1059 (2007).

19. Thariat, J., Hannoun-Levi, J.-M., Myint, A. S., Vuong, T. \& Gérard, J.-P. Past, present, and future of radiotherapy for the benefit of patients. Nat. Rev. Clin. Oncol. 10, 52-60 (2013).

20. Schaue, D. \& McBride, W. H. Opportunities and challenges of radiotherapy for treating cancer. Nat. Rev. Clin. Oncol. 12, 527-540 (2015).

21. Wardman, P. Chemical radiosensitizers for use in radiotherapy. Clin. Oncol.19, 397-417 (2007).

22. Kwatra, D., Venugopal, A. \& Anant, S. Nanoparticles in radiation therapy: a summary of various approaches to enhance radiosensitization in cancer. Transl. Cancer Res. 2, 330-342 (2013).

23. Chen, W. \& Zhang, J. Using nanoparticles to enable simultaneous radiation and photodynamic therapies for cancer treatment. J. Nanosci. Nanotechnol. 6 , 1159-1166 (2006).

24. Hainfeld, J. F., Dilmanian, F. A., Slatkin, D. N. \& Smilowitz, H. M. Radiotherapy enhancement with gold nanoparticles. J. Pharm. Pharmacol. 60, 977-985 (2008).

25. Mirjolet, C. et al. The radiosensitization effect of titanate nanotubes as a new tool in radiation therapy for glioblastoma: a proof-of-concept. Radiother. Oncol. 108, 136-142 (2013).

26. Retif, P. et al. Nanoparticles for radiation therapy enhancement: the key parameters. Theranostics 5, 1030 (2015).

27. Bonvalot, S. et al. First human study testing a new radio enhancer using nanoparticles (NBTXR3) activated by radiation therapy in patients with locally advanced soft tissue sarcomas. Clin. Cancer Res. 23, 908-917 (2017).

28. Maggiorella, L. et al. Nanoscale radiotherapy with hafnium oxide nanoparticles. Fut. Oncol. 8, 1167-1181 (2012).

29. Marill, J. et al. Hafnium oxide nanoparticles: toward an in vitro predictive biological effect? Radiat. Oncol. 9, 150 (2014).

30. Formenti, S. C. \& Demaria, S. Combining radiotherapy and cancer immunotherapy: a paradigm shift. J. Natl. Cancer Inst. 105, 256-265 (2013).

31. Postow, M. A. et al. Immunologic correlates of the abscopal effect in a patient with melanoma. N.Engl. J. Med. 366, 925-931 (2012).

32. Wang, C. et al. Synergistic assembly of heavy metal clusters and luminescent organic bridging ligands in metal-organic frameworks for highly efficient $\mathrm{X}$ ray scintillation. J. Am. Chem. Soc. 136, 6171-6174 (2014).

33. Lan, G. et al. Nanoscale metal-organic layers for deeply penetrating X-rayinduced photodynamic therapy. Angew. Chem. 129, 12270-12274 (2017).

34. Lu, K. et al. Low-dose X-ray radiotherapy-radiodynamic therapy via nanoscale metal-organic frameworks enhances checkpoint blockade immunotherapy. Nat. Biomed. Eng., https://doi.org/10.1038/s41551-018-0203-4 (2018).

35. $\mathrm{Xu}, \mathrm{R}$. et al. Nanoscale metal-organic frameworks for ratiometric oxygen sensing in live cells. J. Am. Chem. Soc. 138, 2158-2161 (2016).

36. Cavka, J. H. et al. A new zirconium inorganic building brick forming metal organic frameworks with exceptional stability. J. Am. Chem. Soc. 130, 13850-13851 (2008).

37. Dai, R. et al. Electron crystallography reveals atomic structures of metal-organic nanoplates with M12 $(\mu 3-\mathrm{O}) 8(\mu 3-\mathrm{OH}) 8(\mu 2-\mathrm{OH}) 6(\mathrm{M}=\mathrm{Zr}$, $\mathrm{Hf}$ ) secondary building units. Inorg. Chem. 56, 8128-8134 (2017).

38. Bonner, W. M. et al. $\gamma \mathrm{H} 2 \mathrm{AX}$ and cancer. Nat. Rev. Cancer 8, 957-967 (2008).

39. Fernandez-Capetillo, O., Lee, A., Nussenzweig, M. \& Nussenzweig, A. H2AX: the histone guardian of the genome. DNA Repair3, 959-967 (2004).

40. Obeid, M. et al. Calreticulin exposure is required for the immunogenicity of $\gamma$ irradiation and UVC light-induced apoptosis. Cell Death Differ. 14, 1848-1850 (2007).

41. Misawa, M. \& Takahashi, J. Generation of reactive oxygen species induced by gold nanoparticles under $\mathrm{x}$-ray and UV Irradiations. Nanomed. Nanotechnol. Biol. Med. 7, 604-614 (2011).
42. Reynders, K., Illidge, T., Siva, S., Chang, J. Y. \& De Ruysscher, D. The abscopal effect of local radiotherapy: using immunotherapy to make a rare event clinically relevant. Cancer Treat. Rev. 41, 503-510 (2015).

43. Formenti, S. C. \& Demaria, S. Radiotherapy to convert the tumor into an in situ vaccine. Int. J. Radiat. Oncol. Biol. Phys. 84, 879-880 (2012).

44. Lugade, A. A. et al. Local radiation therapy of B16 melanoma tumors increases the generation of tumor antigen-specific effector cells that traffic to the tumor. J. Immunol. 174, 7516-7523 (2005).

45. Lee, Y. et al. Therapeutic effects of ablative radiation on local tumor require CD8+ T cells: changing strategies for cancer treatment. Blood 114, 589-595 (2009).

46. Dovedi, S. J. et al. Acquired resistance to fractionated radiotherapy can be overcome by concurrent PD-L1 blockade. Cancer Res. 74, 5458-5468 (2014).

47. Deng, L. et al. Irradiation and anti-PD-L1 treatment synergistically promote antitumor immunity in mice. J. Clin. Invest. 124, 687 (2014).

48. Twyman-Saint Victor, C. et al. Radiation and dual checkpoint blockade activate non-redundant immune mechanisms in cancer. Nature 520, 373-377 (2015).

49. Formenti, S. C. \& Demaria, S. Systemic effects of local radiotherapy. Lancet Oncol. 10, 718-726 (2009).

50. Schaue, D., Ratikan, J. A., Iwamoto, K. S. \& McBride, W. H. Maximizing tumor immunity with fractionated radiation. Int. J. Radiat. Oncol. Biol. Phys. 83, 1306-1310 (2012).

51. Driessens, G., Kline, J. \& Gajewski, T. F. Costimulatory and coinhibitory receptors in anti-tumor immunity. Immunol. Rev. 229, 126-144 (2009).

52. Pinna, N., Garnweitner, G., Antonietti, M. \& Niederberger, M. Non-aqueous synthesis of high-purity metal oxide nanopowders using an ether elimination process. Adv. Mater. 16, 2196-2200 (2004).

53. Franken, N. A., Rodermond, H. M., Stap, J., Haveman, J. \& Van Bree, C. Clonogenic assay of cells in vitro. Nat. Protoc. 1, 2315-2319 (2006).

\section{Acknowledgements}

We thank Dr. Stephen J. Kron for kindly providing the cell lines. We also thank Dr. Jeffrey S. Murley for experimental advice and acknowledge the National Cancer Institute (U01-CA198989), the University of Chicago Medicine Comprehensive Cancer Center (NIH CCSG: P30 CA014599), the CBI Training Grant (NIH 5T32GM008720-15), and the Ludwig Institute for Metastasis Research for funding support.

\section{Author contributions}

W.L. conceived the project. K.N., G.L., C.C., B.Q., K.L., and N.G. performed the experiments and analyzed the results. K.N., G.L., C.C., T.A., P.R., R.R.W., and W.L. wrote the manuscript.

\section{Additional information}

Supplementary Information accompanies this paper at https://doi.org/10.1038/s41467018-04703-w.

Competing interests: W.L. is founder of RiMO Therapeutics, which licensed the nMOF Technology from the University of Chicago. R.R.W. is an advisor to RiMO Therapeutics. The remaining authors declare no competing interests.

Reprints and permission information is available online at http://npg.nature.com/ reprintsandpermissions/

Publisher's note: Springer Nature remains neutral with regard to jurisdictional claims in published maps and institutional affiliations.

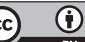

Open Access This article is licensed under a Creative Commons Attribution 4.0 International License, which permits use, sharing, adaptation, distribution and reproduction in any medium or format, as long as you give appropriate credit to the original author(s) and the source, provide a link to the Creative Commons license, and indicate if changes were made. The images or other third party material in this article are included in the article's Creative Commons license, unless indicated otherwise in a credit line to the material. If material is not included in the article's Creative Commons license and your intended use is not permitted by statutory regulation or exceeds the permitted use, you will need to obtain permission directly from the copyright holder. To view a copy of this license, visit http://creativecommons.org/ licenses/by/4.0/.

(C) The Author(s) 2018 